8-1-2019

\title{
Family planning and youth in West Africa: Mass media, digital media, and social and behavior change communication strategies
}

Sarah Castle

Martha Silva

Follow this and additional works at: https://knowledgecommons.popcouncil.org/departments_sbsr-rh

Part of the Health Communication Commons, and the Public Health Commons

How does access to this work benefit you? Let us know!

\section{Recommended Citation}

Castle, Sarah and Martha Silva. 2019. "Family planning and youth in West Africa: Mass media, digital media, and social and behavior change communication strategies," Breakthrough RESEARCH Literature Review. Washington, DC: Population Council. 


\section{LITERATURE REVIEW}

\section{Family Planning and Youth in West Africa: Mass media, digital media, and social and behavior change communication strategies}

AUGUST 2019

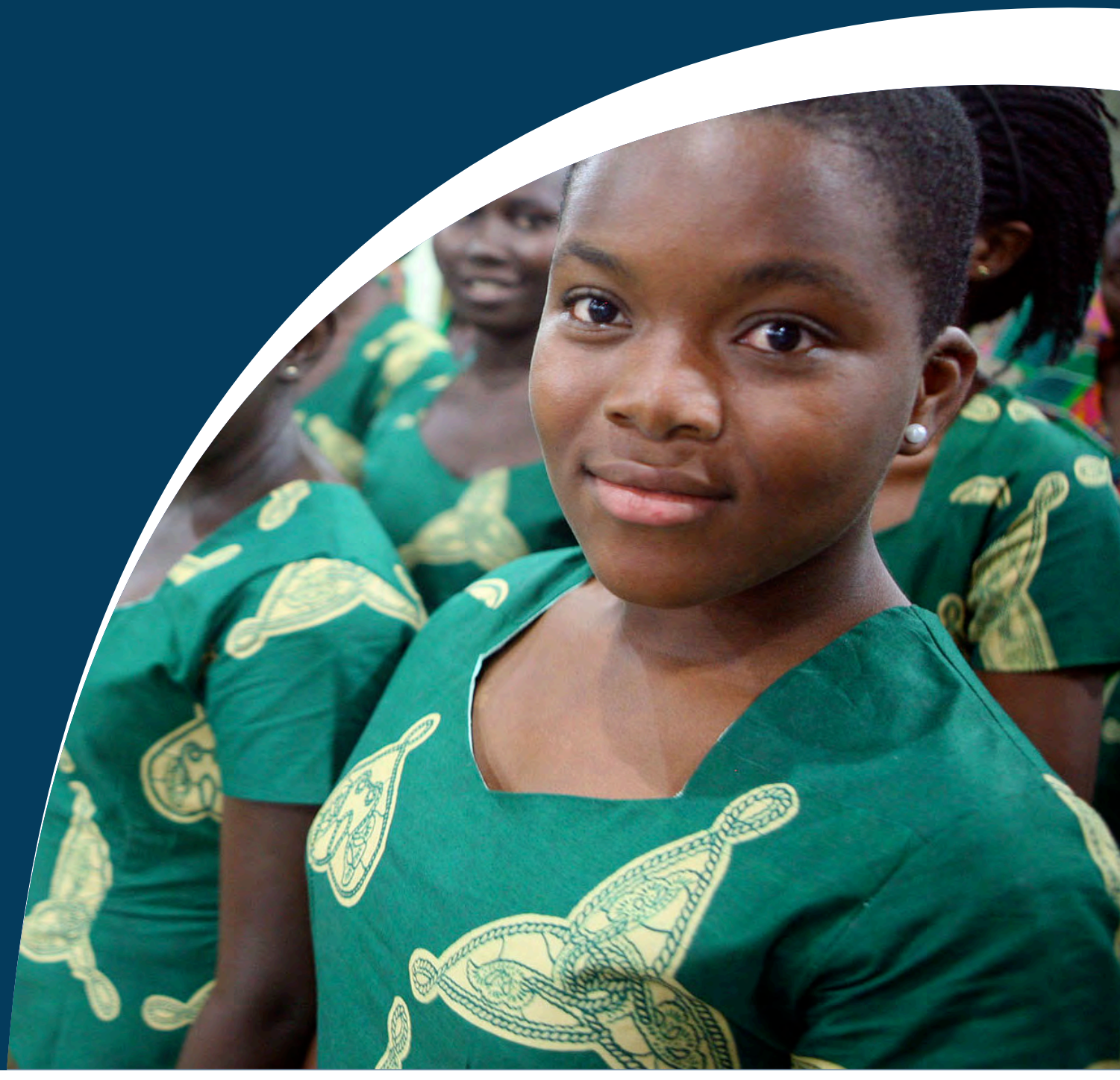

(3) USAID

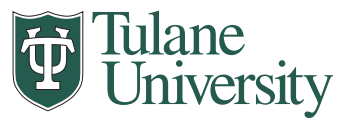




\section{Acknowledgments}

Sarah Castle, consultant, developed the literature review report. Martha Silva of Tulane University conceptualized the literature review and provided extensive technical review of the document. Alison Collier, consultant, edited the report. Sherry Hutchinson of the Population Council provided additional editorial support and laid out the report.

\section{USAID}

Breakthrough RESEARCH is made possible by the generous support of the American people through the United States Agency for International Development (USAID) under the terms of cooperative agreement no. AID-OAA-A-17-00018. The contents of this document are the sole responsibility of the Breakthrough RESEARCH and Population Council and do not necessarily reflect the views of USAID or the United States Government.

\section{它Tulane U) University}

As stewards of the first school of public health in the United States, the Tulane University School of Public Health and Tropical Medicine cultivates independent thinkers, innovative leaders, fierce advocates, and accomplished scholars.

From the neighborhoods of New Orleans to communities worldwide, we conduct research and collaborate with our partners to ensure that all of humanity has an equitable opportunity to be healthy and pursue optimal well-being.

We train the problem solvers. Find us on the Front Lines.
(C)2019 The Population Council. All rights reserved.

Cover photo by (C2008 Sean Hawkey, Courtesy of Photoshare.

\section{Suggested Citation}

Castle, Sarah, and Martha Silva. 2019. "Family planning and youth in West Africa: mass media, digital media, and social and behavior change communication strategies," Breakthrough RESEARCH Literature Review. Washington DC: Population Council.

\section{Contact}

4301 Connecticut Avenue NW, Suite 280 | Washington, DC 20008 +1202 2379400 | BreakthroughResearch@popcouncil.org breakthroughactionandresearch.org
The Population Council confronts critical health and development issuesfrom stopping the spread of HIV to improving reproductive health and ensuring that young people lead full and productive lives. Through biomedical, social science and public health research in about 50 countries, the Council works with our partners to deliver solutions that lead to more effective policies, programs, and technologies to improve lives worldwide. Established in 1952 and headquartered in New York, the Council is a nongovernmental, nonprofit organization with an international board of trustees.

\section{Breakthrough RESEARCH FOR SOCIAL \& BEHAVIOR CHANGE}

Breakthrough RESEARCH catalyzes social and behavior change (SBC) by conducting state-of-the-art research and evaluation and promoting evidence-based solutions to improve health and development programs around the world. Breakthrough RESEARCH is a consortium led by the Population Council in partnership with Avenir Health, ideas42, Institute for Reproductive Health at Georgetown University, Population Reference Bureau, and Tulane University. 


\section{Family Planning and Youth in West Africa: Mass media, digital media, and social and behavior change communication strategies}

\author{
Sarah Castle
}

\author{
Martha Silva
}

\section{Contents}

List of acronyms .................. ii

Executive summary ................ 1

International, regional, and national

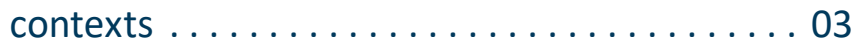

Methodology ..................... 05

Audience heterogeneity with regard to young people and FP 06

Mass media and digital technology in sub-Saharan Africa.

Mass media, digital media, and health-related communication and behavior change. . . . . . . . . . . . . . 09

Evidence of impact of mass media and digital media interventions on FP . . . . . . . . 12

Mass media and FP ................... 12

Digital media and FP . . . . . . . . . . . . . 14

Summary of evidence and gaps
Cost effectiveness of mass media and digital media programs . . . . . . . . . . . 18 Specific lessons learned from selected mass media and digital media initiatives to improve FP behaviors among young people . . . 20

Mass media ..................... 20

Digital media. . . . . . . . . . . . . . . . . . . . 21

Potential need for an adapted behavior change model to accommodate young people's online presence and interactions . . . 25

Conclusions. . . . . . . . . . . . . . . . . . . . 27

Recommendations... . . . . . . . . . . . . 29

References ...................... 30

Annex

Selected mass media and social/digital media interventions around SRH and FP: approaches, evaluation methods, impact and lessons learned. 34 


\section{List of Acronyms}

$\begin{array}{ll}\text { CLV } & \text { C'est la Vie } \\ \text { CS4FP } & \text { Civil Society for Family Planning + } \\ \text { DALY } & \text { Disability-adjusted life year } \\ \text { DPT3 } & \text { Diphtheria, pertussis (whooping cough), and tetanus } \\ \text { FP } & \text { Family planning } \\ \text { HC3 } & \text { Health Communication Capacity Collaborative } \\ \text { HIP } & \text { High impact practices } \\ \text { HIV } & \text { Human immunodeficiency virus } \\ \text { ICER } & \text { Incremental cost-effectiveness ratio } \\ \text { ICT } & \text { Information and communication technology } \\ \text { KJK } & \text { Keneya Jemu Kan } \\ \text { LMIC } & \text { Low- and middle-income country } \\ \text { MCH } & \text { Maternal and child health } \\ \text { MOTECH } & \text { Mobile technology for community health } \\ \text { MSI } & \text { Marie Stopes International } \\ \text { OP } & \text { Ouagadougou Partnership } \\ \text { PSI } & \text { Population Services International } \\ \text { RAES } & \text { Réseau africain de la santé/African Health Network } \\ \text { RCT } & \text { Randomized controlled trial } \\ \text { SMS } & \text { Short message service } \\ \text { SRH } & \text { Sexual and reproductive health } \\ \text { TTM } & \text { Transtheoretical Model (of Behavior Change) } \\ \text { USAID } & \text { United States Agency for International Development } \\ \text { VOD } & \text { Video on demand } \\ \text { WHO } & \text { You Onld Health Organization } \\ \text { YOLO } & \end{array}$




\section{Executive Summary}

\section{This review presents evidence about the impact of mass media and digital media on young people's family planning (FP) attitudes and behaviors. It primarily focuses on the Ouagadougou Partnership countries, but also describes lessons learned from other initiatives implemented more widely in Africa and elsewhere.}

Due to the paucity of FP evidence, the review also includes material from higher income countries where mass and digital media have been used in communication initiatives to prevent non-communicable diseases. In addition, it draws on studies from low- and middleincome countries where such media have been used to create demand for maternal and child health services.

Mass media is classified as a "proven practice" by the United States Agency for International Development's High Impact Practices brief and is documented as being both impactful and cost-effective, although there are few studies which measure these outcomes in relation to young people. By contrast, digital media (including social media) is denoted as a "promising practice" with regard to contraceptive decision-making. It is emphasized that the programmatic distinction between mass media and digital media is somewhat arbitrary, as many initiatives use multiple communication platforms (including outreach and interpersonal communication) in order to convey health-related messages. Evidence suggests that multi-pronged interventions involving a variety of channels are likely to enhance impact, notably through the phenomenon of a "dose response."

There are comparatively few objective evaluations of the impact of digital media on FP behaviors, or on other aspects of health-related behaviors, despite its tremendous reach and potential among youth. The lack of robust evidence can be attributed to the relatively recent development of the channel, as well as to the fact that such campaigns (for example, using WhatsApp or Facebook) are often youth-led and implemented. Youth participation and leadership are very important for creating credible, acceptable messages, yet, young people may need support in evaluating outcomes of these media campaigns. For example, many projects simply measure online views, shares, or likes of their social media posts related to FP and do not analyze, or even document, the demographic and socioeconomic characteristics of campaign followers, which would allow targeted audiences to be segmented in future campaigns. This is particularly relevant to adolescents who are such a diverse group and have different priorities with regard to their contraceptive needs and fertility expectations, for example, in relation to their marital and educational status and employment aspirations.

Digital media, and in particular social media, can be used to raise awareness about FP among young people, as well as to promote specific demand-creation events and for advocacy. The Jeunes Ambassadeurs pour la Planification Familiale have been particularly active in these domains in Francophone Africa. However, there is a need for improved technical support of their social media initiatives in order to enable them to robustly assess the impact of their digital and online activity. It is noted that such evaluations may need to move away from randomized controlled trials to, for example, preand post-intervention surveys. Young activists can also be encouraged to use qualitative research to better understand the processes of change in attitudes and behavior catalyzed by their online activity. Consistent digital media definitions and better audience identification and segmentation combined with robust monitoring and evaluation will improve knowledge about the impact of this channel on young people's FP attitudes and behaviors and make it more appealing to donors, governments and implementers alike.

The review notes that although many FP programs use behavior change models, such as the Transtheoretical Model of Behavior Change, these tend to place importance on interpersonal communication (for example, face-to-face testimonies by satisfied users) as a means to persuade potential adoptors. The dynamics of these face-to-face interactions are significantly different from online exchanges which, on the one hand, can lead to the efficient sharing of viable information to generate demand, but on the other can potentially lead to the propagation of myths and rumors which are the bane of FP programs in the region. It is suggested that the 
behavior change models may benefit from being adapted to recognize young people's considerable digital presence and the different nature of interpersonal interactions from those conducted online. Further research is needed to understand the role of digital media, and, in particular, the way it influences FP attitudes and behaviors both positively and negatively.

With regard to cost-effectiveness, evidence from health domains other than FP suggest that communication via mass media can be very cost-effective. For example, in Burkina Faso, radio campaigns were shown to significantly improve child survival and use of maternal and child health services and to create considerable economies of scale. To date, there is little evidence about the cost-effectiveness of digital media initiatives promoting FP. It is of note that connectivity and mobile phone or computer usage is higher in urban areas and among educated cohorts. These individuals are more likely to already use FP and are probably already more receptive to related messages than their rural and less educated counterparts.

In summary, the evidence suggests that, as part of multi-pronged initiatives, mass media and digital media comprise significant potential for improving knowledge, attitudes, and behavior with regard to FP communication programs among youth. However, to date, digital media lacks rigorous evidence of impact that could catalyze more investment by donors and stakeholders. In all likelihood, its enormous and rapidly increasing reach among young people in Africa and elsewhere urgently necessitates objective evaluations of its effectiveness in order for it to become a proven rather than promising practice for FP programs.

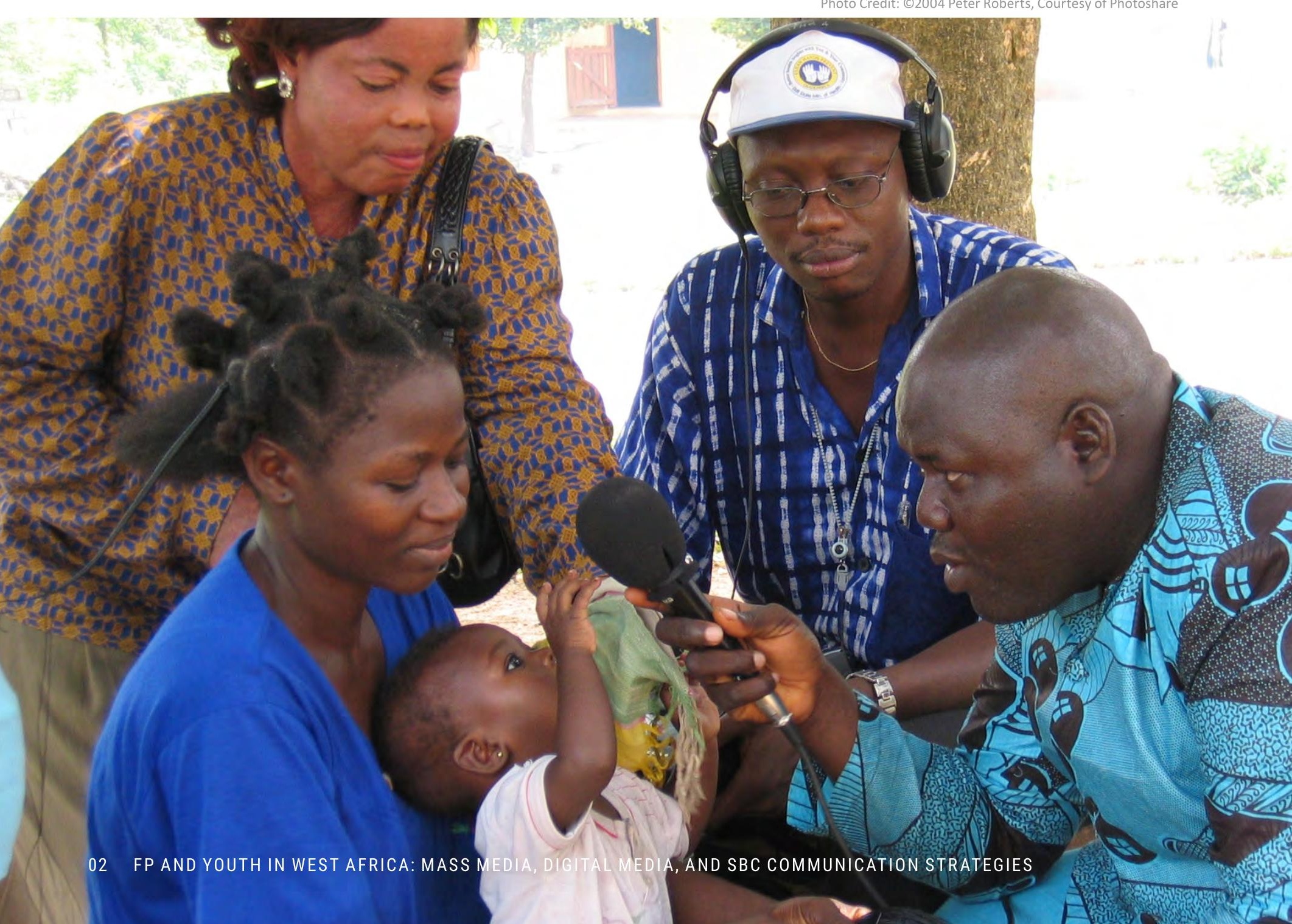




\section{International, regional, and national contexts}

This review seeks to assess the nature, scope, and, where possible, the impact of mass media and digital media initiatives $^{1}$ on family planning (FP) knowledge, attitudes, and behaviors among young people in West Africa. It explores both published and grey literature and also generated information from a small number of interviews with selected key informants. The focus is on the countries of the Ouagadougou Partnership (OP) $)^{2}$ but it also draws on a number of pertinent examples from elsewhere on the continent as well as a small number within the global context. The key lessons learned are summarized along with reflections about possible research and programmatic pathways which could be undertaken to address the gaps identified.

While there are one billion young people ages 10-24 living in the 69 FP2020 focus countries, many do not have access to the necessary high-quality sexual and reproductive health care programs or information that could empower them to determine matters related to their own sexuality. ${ }^{3}$ The FP2020 framework recognizes that, unfortunately, stigma, discrimination, and a lack of information prevent many young people from accessing and using modern forms of contraception. This review discusses the roles of mass media and digital media in providing young people with high quality information

\footnotetext{
${ }^{1}$ While mass media refers to television, radio, and print media, accepted definitions of digital media include internet, text and voice messaging, and social media including networking sites such as Facebook and apps such as WhatsApp (Guse et al. 2012). It should be noted that this review is not concerned with initiatives which use mobile phones to, for example, enable health workers to remind clients of appointments, or for hotlines, even though in some studies (see Braun et al. 2013, Källander et al. 2013) these are considered "digital media" interventions. The review stresses the need for consistent definitions of what constitutes digital media in the context of FP programming and other health interventions.

${ }^{2}$ The Partnership was launched in Ouagadougou, Burkina Faso in February 2011 at the Regional Conference on Population, Development and Family Planning held by the nine governments of Francophone West African countries (Benin, Burkina Faso, Côte d'Ivoire, Guinea, Mali, Mauritania, Niger, Senegal, and Togo) and their technical partners. It seeks to mobilize financial resources to accelerate progress in the use of FP services in the Partnership countries (https://partenariatouaga.org/en/).

${ }^{3}$ www.familyplanning2020.org/ayfp
}

about FP methods and services. It also explores how media can create an enabling environment for FP uptake and shape peer norms to facilitate sustained use within the context of considerable social, geographic, and economic barriers.

WHILE THERE ARE ONE BILLION YOUNG PEOPLE AGES 10-24 LIVING IN THE 69 FP2020 FOCUS COUNTRIES, MANY DO NOT HAVE ACCESS TO THE NECESSARY HIGH-QUALITY SEXUAL AND REPRODUCTIVE HEALTH CARE PROGRAMS OR INFORMATION THAT COULD EMPOWER THEM TO DETERMINE MATTERS RELATED TO THEIR OWN SEXUALITY.
Sustainable Development Goal 9 comprises a commitment to "significantly increase access to information and communications technology and to strive to provide universal and affordable access to the Internet in least developed countries by 2020" (International Telecommunications Union 2018). This goal complements the acknowledgment by the OP that mass and digital media can play an important role in increasing FP knowledge and uptake among young people within the region. ${ }^{4}$ Youth-related activities are central to the OP's ethos given the young structure of the countries' populations and the pressing need to capitalize on the demographic dividend. ${ }^{5}$ Within the nine OP focus countries, the Jeunes

\footnotetext{
${ }^{4}$ https://partenariatouaga.org/en/resource/ works-improve-young-peoples-sexual-reproductive-health

${ }^{5}$ https://partenariatouaga.org/en/resource/ high-level-symposium-demographic-dividend-africas-development
} 
Ambassadeurs de la PF comprises a youth-focused and youth-implemented initiative, which is discussed in detail later. The "Youth Ambassadors" set an agenda targeting young people on their own terms and recognize that mass and digital media are increasingly important, if not one of the main channels of communication among younger age groups (Resopopdev 2019). ${ }^{6}$

On a national level, although mass media are given some attention in countries' strategic plans which seek to address adolescent reproductive health, digital media initiatives (and associated budget allocations) are less prominent. For example, in Côte d'Ivoire gender differences in media access are highlighted in the national plan for adolescent health which describes how "media are the most frequently used channels for the diffusion of information but within the Ivorian population, 40 percent of young women aged 15-24 are not regularly exposed to television, radio, written press, compared with 26 percent of young men" (Ministère de la Santé et de la Lutte conte le SIDA 2016). Nevertheless, the plan acknowledges that "it is possible that these age groups are using digital media more frequently than other sectors of the population." In Burkina Faso, mass media initiatives were highlighted in the strategic plan for adolescent reproductive health as a means of creating an enabling environment for improved youth-friendly services. The plan outlines how intergenerational communication could be improved by radio and television initiatives accompanied by face-to-face debates as well as by peer education (Ministère de la Santé 2015). However, in general, digital technologies and their implications for the communication of reproductive health information are given little attention, despite being widely used by young people, particularly in urban areas (but also increasingly in rural communities) both in Burkina and indeed throughout the Sahel (Castle 2017).

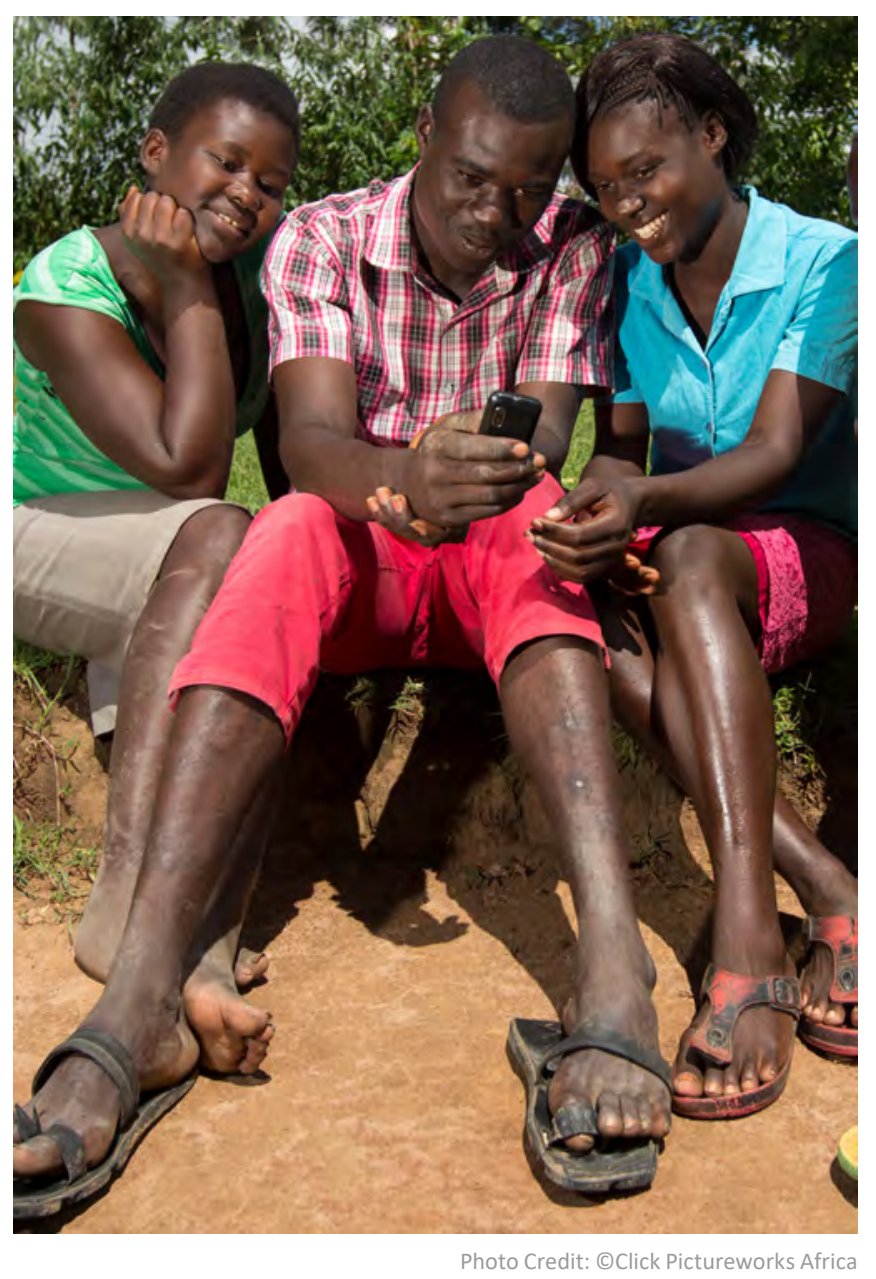

\footnotetext{
${ }^{6}$ Other regional initiatives include The Sahel Women's Empowerment and Demographics project which, as part of its activities, will launch a regional media campaign for behavior change using radio, television, newspaper, and digital media. The Regional Strategy for Social and Behavior Change Communication (2017-2019) aims to promote the empowerment of women and adolescent girls by changing behaviors and attitudes to improve their RH knowledge, and to promote voluntary FP, as well as improve their access to and use of reproductive, maternal, neonatal and child health, and nutrition services (UNFPA/WCARO 2017). The program is not described in this review as it has not yet started these activities and thus no information or evaluation is available.
} 


\section{Methodology}

As described, the literature review sought to collate evidence about mass media, digital media, and FP in relation to the OP countries. Originally it was to focus specifically on Burkina Faso, Côte d'Ivoire, Niger, and Togo, but there turned out to be comparatively little information for these countries, nor for others in the OP. Thus, the search was widened to include such initiatives from throughout Africa and a small number of studies with relevant learning from elsewhere. Although the impact of mass media on health-related behaviors (though not necessarily in relation to FP) was well documented (Naugle and Hornik 2014), such studies were relatively scarce with regard to digital media. Nevertheless, as robustly evaluated evidence exists with regard to the success of mass media (and to some extent of digital media) for the prevention of non-communicable diseases in higher income countries (Durkin, Brennan, and Wakefield 2012; Farley 2015, Peiris et al. 2014; Dallery et al. 2015), a brief review of this literature was also undertaken. In addition, the review was broadened to include media campaigns that had sought to improve knowledge and change behavior with regard to maternal and child health in low- and middle-income countries (LMICS). Additional FP initiatives in the OP countries targeting young people's attitudes and behavior showing promising but still unevaluated results were also included. These (including the work of the Jeunes Ambassadeurs described above) are discussed in detail below as, even without objective evidence, they nevertheless generate potentially important areas of reflection and learning.

The documents and evidence reviewed below were obtained from the online databases Popline, Medline, and Google Scholar, as well as the HC3 Family Planning Evidence Database. Key words such as "mass media," "radio," " television," "digital media," "social media," "internet," "mHealth," "family planning," "contraception," "reproductive health," "youth," "adolescents," "behavior change," and "Africa" were used. Similar terms were searched in French. Project-specific online data and reports were obtained from relevant initiatives such as FP2020, The OP, HC3, Passages, and Adolescent 360, as well as from relevant government websites if available. In addition, a large number of emails were sent to relevant actors and stakeholders in order to obtain grey literature, including reports and project evaluations, including to the Population Reference Bureau, Marie Stopes International (MSI), Population Services International (PSI), Development Media International, and RAES (Réseau africain de la santé, a Senegalese nongovernmental organization behind a popular television production aimed at youth). A number of these email exchanges resulted in follow-up phone calls and Skype conversations, for example, with the Director of Etrilabs which coordinates communication initiatives for the $\mathrm{OP}$, with the Director of Civil Society for Family Planning (CS4FP Plus) in the OP who oversees the activities of the Jeunes Ambassadeurs, and with the Monitoring and Evaluation officer of RAES. These conversations yielded further important information and insights.

In summary, the review is based on evidence from the following sources:

- Approximately 50 peer reviewed articles refined from an initial selection of over $100^{7}$.

- 52 documents and presentations from the grey literature.

- Email exchanges with 20 key actors in the field, for example, Les Jeunes Ambassadeurs.

- Telephone/Skype conversations with three key informants (The Director of EtriLabs, $M$ and $E$ officer at RAES, and Director of CS4FP in the OP).

${ }^{7}$ Articles were not considered if they were more than 10 years old or, for example, if, in the case of mobile phone technologies, they evaluated the use of mobile phones purely as reminders about clinic appointments. Articles which focused on developed country evidence were also minimized. 


\section{Audience heterogeneity with regard to young people and FP}

The World Health Organization (WHO) defines "adolescents" as individuals between 10 and 19 years of age, "youth" between 15 and 24 years, and "young people" between 10 and 24 years (Blum and Nelson-Nmari 2004; Sawyer et al. 2018). Adolescence is a critical life stage comprising a phase of significant physical, cognitive, emotional, and social development. Neurological development combined with hormonal changes and varying social stressors may cause an adolescent to be increasingly susceptible to wide mood swings and reduced impulse control, which are often associated with increased overt sexual curiosity and experimentation (Radzik, Sherer, and Neinstein 2002; Curtis 2015). As adolescents mature, they transition from strong paren-

YOUNG MEN AND YOUNG WOMEN HAVE DIFFERENT INDIVIDUAL AND SOCIETAL EXPECTATIONS WITH REGARD TO REPRODUCTION.

tal control in childhood to greater independence; as their social networks expand beyond their families and neighborhoods, peers have a bigger influence on their opinions, attitudes, and behaviors (Rai et al. 2003). Within this context, mass media and digital media can have an extremely important function in expanding young people's social networks both virtually and in real life and serve to create and share new norms, especially around reproductive health and gender relations (Cookingham and Ryan 2015).
It is necessary to acknowledge that in sub-Saharan Africa, and indeed elsewhere, "youth" comprise an extremely heterogenous group with different priorities and needs. Young men and young women have different individual and societal expectations with regard to reproduction. In addition, the provision of sexual and reproductive health (SRH) information and services for unmarried young women in particular is known to be challenging not least because they may be subject to significant stigma from peers, family members, and health care providers (Aluzimbi et al. 2013). Contraceptive uptake and discontinuation-the latter being more common among young users (Castle and Askew 2015)-are often related to peer group communication which instills a fear of side effects fueled by myths about sterility (Ankomah, Anyanti, and Oladosu 2011; Gueye et al. 2015). In addition, particularly in rural areas, young married women are pressured to begin child bearing soon after marriage to "prove" their fertility to their marital relatives (Bove, Vala-Haynes, and Valeggia 2014). This contrasts with female urban residents who may seek to postpone their childbearing to pursue educational or employment opportunities (Bongaarts, Mensch, and Blanc 2017). Thus, the content of media messages presents numerous challenges to accommodate such audience heterogeneity and diverse world views related to place of residence (urban/rural), marital status, and educational level. To date, most digital media messages have probably reached urban, educated segments who have access to the internet. However, it is noted below that rural youth are increasingly able to access such media, and its content should better evolve to reflect their needs and perspectives. 


\section{Mass media and digital technology in sub-Saharan Africa}

Although it is not within the scope of this report to assess market industry data related to media and internet access, together with phone ownership, selected details are presented here to understand the scale of actual and potential reach for FP messages, especially to young people.

Turning first to mass media (namely television ${ }^{8}$ ), in 2015, nearly 55.34 million households in sub-Saharan Africa had televisions, a number expected to rise to about 75 million by 2021 (Statista 2019). As of 2016, there were approximately 19.47 million pay television subscribers in the same area. Video-on-demand (VOD) services are also increasing, with more and more people using mobile and

${ }^{8}$ It is discussed below how, in many LMICs and in the Sahel in particular, print media (newspapers, etc.) are likely to be less effective since levels of literacy are low. For that reason, it is not central to the analyses and discussion presented here. digital devices to access television shows and content. The user penetration for VOD, though still relatively low, is expected to grow from 5 percent in 2017 to 8 percent by 2021 (Ubongo 2019).

The Pew Research Center conducts an annual study in six African countries to ask about phone ownership and notes that it has increased rapidly (Pew Research Center 2018). Figure 1 shows that in Senegal in 2017, 34 percent of Senegalese adults reported owning a smartphone, up from 13 percent in 2013. In West Africa, a basic smartphone costs approximately CFA 15,000 (\$25). Even those living in rural areas (where both cost and poor network coverage used to preclude use) are now often able to own one (Senam Beheton, Etrilabs, personal communication 2019). Rural residents who own simple smartphones can, for example, download a basic version of Facebook and do not need phone credit to take advantage of this

FIGURE 1 TYPE OF PHONE OWNED BY ADULTS IN SELECTED SUB-SAHARAN AFRICAN COUNTRIES (2017)
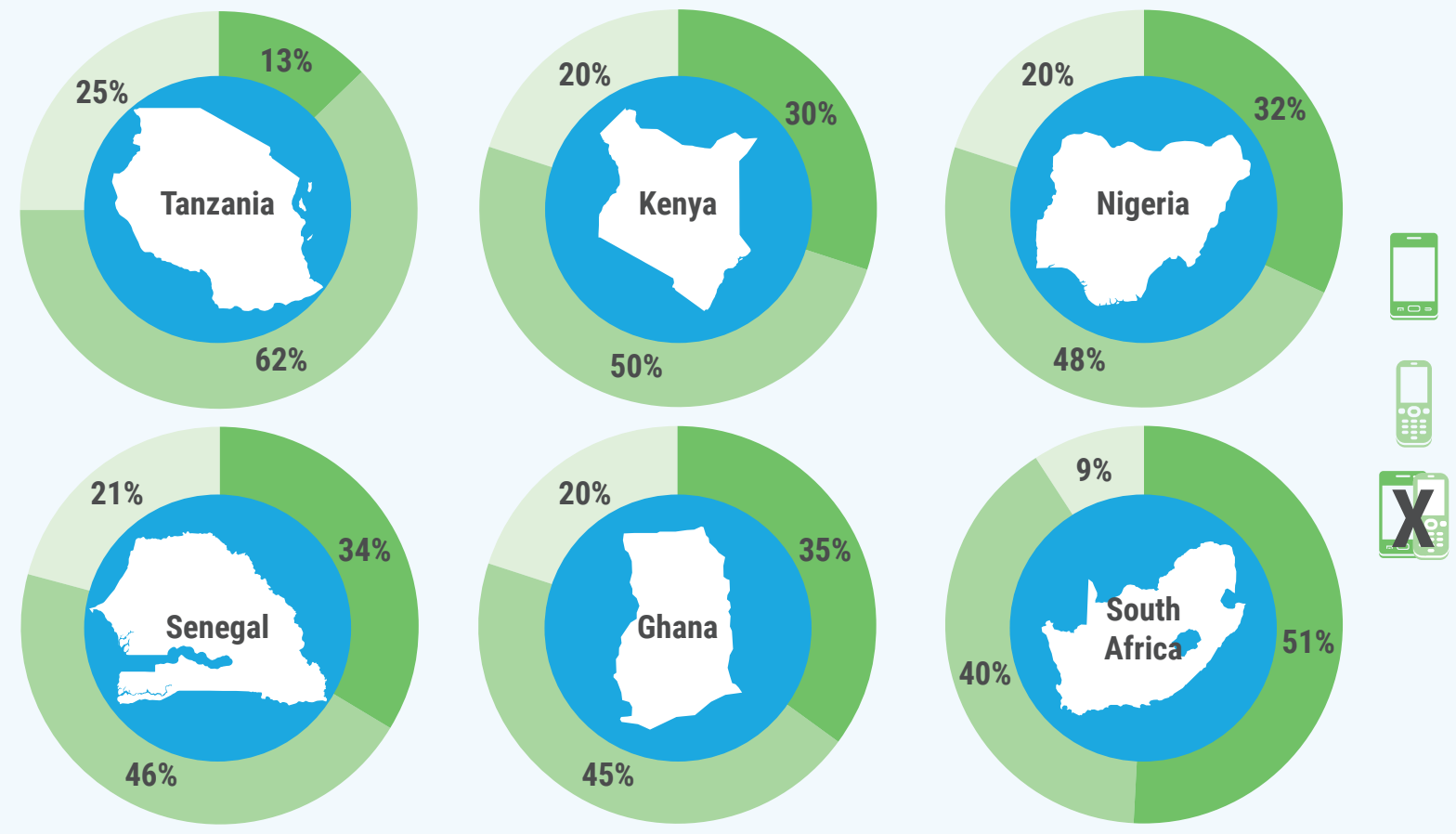

Smart cell phone

Basic phone

Source: Pew Research Center (2018) 
and other apps. In addition, literacy is also no longer a barrier as voice messages can be shared, for example, on WhatsApp, which works successfully with low bandwidth.

Nevertheless, the uptake of smartphones is still inversely proportional to poverty rates. The Pew research found that, in Senegal, 27 percent of those with less than secondary education owned a smartphone compared with 66 percent of those with secondary education or above. Almost half (48 percent) of those with a higher income (defined as being above the national median) owned a smart phone compared with 23 percent with a lower income (below the national median). Thus, it is important when evaluating impact to tease out the independent effect of phone ownership and use from the confounding socioeconomic factors which are known to influence health behaviors and outcomes. In addition, gender disparities in phone ownership need to be acknowledged. Research indicates that globally, a woman is 21 percent less likely to own a mobile phone than a man (Poushter 2016). This is likely to have both direct and indirect implications for SRH. Owning a phone can be empowering for a woman and allow her to access both health and other types of information that she would be unable to otherwise (Alam, Yusuf, and Coghill 2009).

IT IS IMPORTANT WHEN

EVALUATING IMPACT TO TEASE

OUT THE INDEPENDENT EFFECT

OF PHONE OWNERSHIP AND

USE FROM THE CONFOUNDING

SOCIOECONOMIC FACTORS WHICH

ARE KNOWN TO INFLUENCE

HEALTH BEHAVIORS AND

OUTCOMES. older owned a smart phone compared with 32 percent of those aged 30-49 and 46 percent of those aged 18-29 (Pew Research Center 2018). This also has significant implications for audience targeting and indicates that mobile messaging may be the channel of choice for many young people. ${ }^{9}$

In contrast to phone use, the prospects for widespread access to the internet across the continent by 2020 remain poor. Currently, only one quarter (25 percent) of people in sub-Saharan Africa use the internet (Nominet 2016). In the 48 countries categorized by the United Nations as "least developed" (34 of which are in Africa), the proportion of people using the internet is only 15 percent (United Nations Committee for Development Policy 2018). This poor access is partly related to the infrastructure costs of delivering connectivity (via trenches and cables) which are perceived to greatly outweigh the profits that can be made in many environments (Nominet 2016). However, low use in many settings may also be related to less availability of developed content, due to lacking skill capacity (World Economic Forum 2017). The paucity of digital SRH content is identified as problematic and discussed in detail below. This is linked to a lack of, or poor quality, secondary education, which compromises young people's internet potential, both in terms of use and development (including challenges related to digital programming and coding-for example, to develop apps and websites). The strengthening of information technology skills to enable young people to access the internet has been identified as a key factor for countries to capitalize on the demographic dividend (Groth and May 2017). Such skills enable them to not only reap SRH benefits (via, for example, gaining FP information across digital media), but also enhance their potential in other domains, such as education and employment, which have been shown to have a beneficial impact on their health (Hale and Viner 2018).
While mobile phone ownership levels are similar for different age groups, the same is not true of smartphones. In all six countries researched, people ages 18 to 29 are more likely to own smartphones than people ages 50 and older, often substantially so. For example, in Kenya, 41 percent of those under 30 have internet-enabled devices, compared with just 10 percent of people ages 50 and older. In Senegal, 16 percent of those age 50 and
${ }^{9}$ However, it should be noted that, in many Sahelian settings, particularly those in rural areas, many young people do not own personal phones and often share or borrow phones, most commonly from a family member. In addition, in poorer settings, phone ownership can be transient, since young people's phones might also be sold to obtain daily essentials when in need (Livingston et al. 2017). The relatively widespread rural phenomenon of phone sharing has implications for using such a medium to promote FP, as young women may risk disapproval or worse if such messages are read by older relatives. 


\section{Mass media, digital media, and health-related communication and behavior change}

\section{Impact of selected mass media and digital media initiatives on im- proving lifestyle factors related to non-communicable diseases in higher income countries}

Specific evidence on the impact of mass and digital media initiatives relating to FP globally and in a number of selected African settings is presented in detail in the following section, "Evidence of impact of mass media and digital media interventions on family planning." However, as described above, there are relatively few robustly evaluated programs which have documented the impact of such approaches upon contraceptive knowledge and uptake (especially relating to digital technology and specifically relating to youth). It was therefore deemed necessary to briefly describe the impact of mass media and digital media interventions on knowledge and behavior in health-related domains other than FP in both developed and developing country settings. These include first, interventions which seek to address lifestyle factors related to health risks in higher income contexts. Second, a number of evaluations are reviewed where mass and digital media have been used to improve behaviors and outcomes relating to maternal and child health more generally in West Africa.

In higher income countries, much of the literature documents how mass media campaigns have been successfully used to change behavior in order to prevent non-communicable diseases and to improve lifestyle factors which are linked to poor health outcomes (Durkin, Brennan, and Wakefield 2012; Farley 2015). ${ }^{10}$ Wakefield,

\footnotetext{
${ }^{10}$ It is important to note that such impact evaluations are sometimes challenged on methodological grounds because the audiences of mass media programs are not randomly assigned to receive the program "treatment"
}

Loken, and Hornik (2010) carried out a wide-ranging review of the outcomes of mass media campaigns relating to tobacco, alcohol and drug use, heart disease risk factors, road safety, cancer screening and prevention, child survival, and organ or blood donation. They concluded that mass media campaigns can produce positive changes or prevent negative changes in health-related behaviors across large populations. Significantly, their findings emphasized how the importance of the concurrent availability of required services and commodities, together with the existence of community-based programs which support such behavior change, contributed to these outcomes. This underscores the fact that the success of mass media initiatives is likely to be linked to multi-channeled approaches within which quality services are readily available. This may present a challenge for youth in the Sahel or in similar contexts, where despite exposure to media messages, as described above, they are likely to face significant social and geographical barriers in order to access FP and reproductive health services.

Robust evaluations of the impact of digital media on improving health knowledge and behavior are even more poorly documented than those of mass media approaches. The reasons for this are discussed in detail below and, in general, relate to the relatively recent advent of the technology and its comparatively limited systematic use in public health messaging. As noted above, due to this paucity of evidence, it is necessary to examine learning from a number of studies in higher income countries. These have, for example, noted the effective impact of digital technology on smoking cessation and on risk mitigation for other behaviors linked to lifestyle-related morbidity (Peiris et al. 2014; Dallery

(i.e., exposure to the program or to a control condition (Kinkaid and Do 2006). By their nature, mass media programs are designed to reach as many people as possible and exposure is largely determined by the reach of radio and television channels used. 
et al. 2015). For example, in a Cochrane Review of the impact of program-generated mobile phone messages on smoking cessation, it was found that they had a beneficial impact on six-month cessation outcomes (Whittaker, McRobbie, and Bullen 2016). However, the authors note that most included studies examined text message interventions in high-income countries with good tobacco control policies, thus underscoring the importance of a favorable policy environment in order to maximize the impact of such activities. It is also likely that such studies in higher income contexts take place in settings with relatively good, if not universal, network penetration, which is not always the case in LMICs.

\section{Impact of selected mass media and digital media initiatives on maternal and child health outcomes in LMICs}

Selected evidence relating to the impact of mass media and digital media on child survival and maternal and child health initiatives in LMICs was also reviewed. Through a systematic review of the literature, Naugle and Hornik (2014) summarize and evaluate studies which described a mass media intervention (radio, television, newspapers) that targeted a child survival health topic. The studies they included presented quantitative data from an LMIC using an evaluation design that used pre- and post-intervention data, treatment versus comparison groups, or post-intervention data across levels of exposure to assess a behavioral or health outcome. The 111 campaign evaluations that met the criteria were sorted into weak ( $n=33)$, moderate $(n=32)$, and stronger evaluations ( $n=46$ ) based on the sampling method, evaluation design, and efforts to address mass media effects. The authors concluded that robust evaluations provide evidence that mass media campaigns can positively impact a wide range of child survival health behaviors. The potential advantages of mass media include consistent, repetitive messaging to a broad audience, control over message content and delivery, ability to translate into other languages, and relatively low cost per person exposed.

A randomized controlled trial (RCT) in Burkina Faso showed that a child health radio campaign increased under-five consultations at primary health centers for malaria, pneumonia, and diarrhea (Kasteng et al. 2018), resulting in an estimated 7 percent annual reduction in

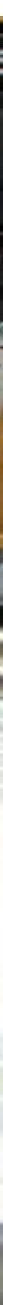


under-five deaths. The authors concluded that saturation-based media campaigns should become mainstream public health interventions, as they are the most cost-effective and scalable way of improving health outcomes in two linked ways. First, they create awareness and encourage healthy behaviors (for household interventions, such as breastfeeding) and second, they facilitate health-seeking behaviors (building demand for services). Media campaigns can be taken to national scale quickly and relatively cheaply, even in countries without strong healthcare service delivery systems. Potential disadvantages include the difficulty of capturing audience attention in an increasingly crowded media environment, the one-way flow of information, and the inability to individually target messages.

Further examples of how such mass media initiatives appear to be effective include the effective promotion of insecticide treated nets in Nigeria (Ankomah et al. 2014) and radio campaigns which resulted in improved uptake of antenatal and postnatal care in Malawi (Zamawe, Banda, and Dube 2016). Regarding the processes by which these improvements occur, in a multi-country analysis using Demographic and Health Survey (DHS) data relating to childhood immunization, Lin et al. (2014) determined that the effects of media use (radio and television) were associated with the relationships between socioeconomic status and vaccine uptake. They concluded that mass media may be an important tool in reducing the health discrepancies between children from high and low socioeconomic backgrounds. Mass media thus overrode any potential differences in vaccine uptake that may otherwise have been due to socioeconomic status.

Turning to digital media, there is less robust evidence for impact in developing country settings with regard to maternal and child health-related behaviors and outcomes. Nevertheless, a number of evaluations have
THE POTENTIAL ADVANTAGES OF MASS MEDIA INCLUDE CONSISTENT, REPETITIVE MESSAGING TO A BROAD AUDIENCE, CONTROL OVER MESSAGE CONTENT AND DELIVERY, ABILITY TO TRANSLATE INTO OTHER LANGUAGES, AND RELATIVELY LOW COST PER PERSON EXPOSED.

shown some significant impacts. These include mobile phone messaging improving antenatal care among pregnant women in Nigeria (Oyeyemi and Wyn 2014) and for improving skilled attendance at delivery in Zanzibar (Lund et al. 2012). Among HIV-positive women in South Africa, participants in a mobile phone intervention were more likely than controls to attend all recommended antenatal and postnatal visits and their offspring were more likely to receive all recommended first year vaccinations. Birth outcomes of intervention participants improved, as they had an increased chance of a normal vaginal delivery and a lower risk of delivering a low-birth weight infant (Coleman 2018). In a review of the influence of the use of information and communication technology (ICT) for delivering maternal and child health $(\mathrm{MCH})$ information and services to target populations, Obasola, Mabawonku, and Lagunju (2015) reviewed a total of 18 relevant articles. The authors concluded that the impact was such that there was a need to move the application of ICT for $\mathrm{MCH}$ care from pilot initiatives to interventions on a sub-regional scale. 


\section{Evidence of impact of mass media and digital media interventions on FP}

This section presents an overview of available evidence as to the impact of mass media and digital media on FP knowledge and behavior. It draws on a number of global reviews and synthesized findings as well as a small number of multi-country studies in both OP countries and elsewhere ${ }^{11}$. Learning and gaps related to the studies reviewed are presented in Table 1 (pg 16). Individual or single-country mass media or digital media initiatives are not considered in this section (except as part of syntheses or reviews). Rather, these (even those which are small-scale, relatively recent, or not robustly evaluated but nevertheless show promising approaches) are discussed later on in detail along with additional potential learning in the lessons learned section (pg 20).

\section{Mass media and FP}

The High Impact Practices (HIPs) brief on mass media and FP (HIPs 2017) provides a useful summary of documented evidence of the effectiveness of such interventions to date. It notes that mass media has been shown to have a proven impact on FP attitudes and uptake although the evidence does not specifically address its impact on youth. Mass media can influence individual behaviors by providing accurate information, building self-efficacy, and promoting positive attitudes and social norms. It can be lead to improved knowledge about fertility and contraception, clarify misperceptions about the risk of unintended pregnancy, dispel myths about side-effects, and challenge perceived norms that discourage FP and contraceptive use. It is thus a particularly suitable medium for youth, although there is little evidence comparing the relative effectiveness of mass media campaigns on young people's FP knowledge and behavior compared with that of older individuals.

\footnotetext{
${ }^{11}$ Although some of the reviewed articles relate to youth, as described elsewhere in this review, the number of such studies comprising robust evaluation of impact is limited. Thus, research findings pertaining more generally to women of reproductive age have also been included.
}

The HIP brief reviewed 12 studies that showed a statistically significant effect of exposure ${ }^{12}$ to mass media campaigns on modern contraceptive use. Differences in contraceptive use between those exposed and unexposed to mass media, reported in nine of the studies, ranged from 5 to 27 percentage points, with exposure to mass media leading to higher likelihood of contraceptive use. Five studies that reported odds ratios found that those exposed to mass media were up to twice as likely to use modern contraception than those not exposed.

The 12 studies highlighted effective programs designed for both men and women of reproductive age. Based on the seven studies that collected demographic characteristics, mass media programs were more likely to reach individuals in higher wealth quintiles as well as participants who were urban, younger, and had lower parity. Six used radio or television serial dramas with 13 to 26 episodes running from six months to two years and including promotional ads on FP. Six of the evaluations measured exposure to solely mass media content. An additional five studies measured exposure to mass media combined with more approaches, such as community mobilization. Although other components may have played a role, at least eight of the mass media programs showed linkages to service delivery improvements, such as social franchising, and at least seven of the programs included community-based activities such as outreach. This underscores the fact that mass media initiatives are often just one component of a more multi-faceted program comprising other elements such as interpersonal communication and service provision. A weakness of the evaluations of many such initiatives is that they are unable to identify the net effect of the mass media intervention as opposed to the separate or combined effects of the other elements. Additional evidence suggests that mass media may serve to increase interpersonal communication (including spousal communication) and even indirectly impact those who were not exposed to

\footnotetext{
12"Exposure is often determined by self-report on a 'yes' or 'no' basis. Few studies assessed frequency or intensity of participant exposure to programming." https://www.fphighimpactpractices.org/briefs/mass-media
} 
the original messages, making them look more favorably upon FP and other reproductive health issues (Bablola, Figueroa, and Krenn 2017). However, evidence from outside Africa suggests this improvement in spousal communication may be limited to groups of higher socioeconomic status (Suryawanshi et al. 2016). Clearly, more research is required to explore this important issue.

The HC3 FP Evidence Database ${ }^{13}$ presents a collection of 249 articles describing interventions or studies that address the impact of social and behavioral change communications approaches on FP attitudes and behaviors. Tellingly, 98 studies are identified if the filter of "mass media" is applied while just 10 appear if the filter of "new media" (comprising digital media) is used. Importantly the "mass media" articles stretch back over 30 years whereas those identified as "new media" are relatively recent (mainly within the last 7 to 8 years). This underscores how the field is comparatively new and how, to date, there is a lack of objective evaluation of the use of digital media within FP programs.

The "mass media" filtered search within the HC3 database identified, among other studies, an evaluation of the communication elements of the Urban Reproductive Health Initiative, which was carried out in India, Kenya, Nigeria, and Senegal (Winston et al. 2018). The research found that in Senegal, the use of mass media was significantly associated with the subsequent use of modern contraception (Sougou et al. 2017). The program used a variety of different communication channels including television, radio, and newspapers. The analysis of the data showed that the use of television and radio had a significant impact on the adoption of an FP method. On the other hand, the use of newspapers as a means of distributing FP news had no impact on the adoption of modern FP methods. Sougou et al. (2017) noted that according to the Ministry of Health of Senegal, the majority of Senegalese women (82 percent) do not consult any newspaper or magazine. Women use radio as their main mass media channel (70 percent), followed by television (56 percent) and newspapers (14 percent). The study did not break down media use or its effect on FP behavior among young people, again pointing to a need for youth-specific studies of media impact.

The Nigeria Urban Reproductive Health Initiative evaluation notes a dose response in terms of exposure to FP messages from both mass media and other sources such

${ }^{13} \mathrm{https} / / /$ healthcommcapacity.org/family-planning-evidence-database/ as community sensitization (Krenn et al. 2014). Three years into the initiative in four Nigerian cities, an analysis of longitudinal data showed that use of modern contraceptives had increased in each city, varying from 2 to 16 percentage points, and that the observed increases were predicted by exposure to Nigeria Urban Reproductive Health Initiative activities. The more project activities women were exposed to, the greater their contraceptive use. For example, among women not using a modern method at baseline, contraceptive prevalence among those with no exposure by midterm was 19 percent, versus 43 percent among those with high exposure. Project exposure had a positive dose-response relationship with ideation, as did ideation and contraceptive use. The importance of the dose response phenomenon (also discussed in other studies elsewhere in Africa-see Taylor et al. [2010] for HIV and Winters et al. [2018] for Ebola) has programmatic as well as cost repercussions for intervention design around mass media and FP uptake.

Importantly, WHO underscores the importance of a broader rights-based mass media perspective around FP which can benefit from an association with other messaging, for example, to reduce gender-based violence and associated unwanted pregnancy (WHO 2008). Such an approach can comprise communication program involving mass media and interpersonal communication directed at various community members to influence social norms. WHO recommends that these initiatives be combined with discussion sessions, for example, involving adolescent girls to enhance their ability to resist coerced sex by building their self-esteem and life skills in areas such as communication and negotiation, and by improving their links to social networks (including online networks) and their ability to obtain social support. It is shown later on in the "Mass media" section that mass media promoting gender equity and rights-based information about FP may be a necessary condition for improving contraceptive uptake and be particularly influential in changing men's attitudes about a woman's right to use FP.

In general, these findings point to the fact that mass media interventions are likely to have greater success if they occur as part of strategies using multiple media channels and are accompanied by parallel service provision and interpersonal communication activities to enhance demand. However, this often poses methodological challenges in terms of causal attribution as noted by Jacobs (2016) in an analysis of DHS data from Burkina Faso and Senegal. He determined that although 
there was conclusive evidence of the effectiveness of mass media campaigns in changing FP behaviors, there were also substantive difficulties in assessing the isolated effects of mass media on FP use. As noted above, multi-faceted interventions involving multiple message sources are likely to enhance impact notably through a dose response. However, such approaches make it difficult to determine how much of the increased uptake in modern contraceptive use can be attributed to mass media campaigns, as opposed to community outreach, better quality services, and increased access. Some of the effects are likely to be related to both demand creation and improved supply of services, but it is unclear how much mass media also creates an enabling environment to facilitate uptake. In addition, further research is needed to assess how mass media campaigns can impact youth FP behaviors.

\section{Digital media and FP}

The HIPs review of Digital Health for Social and Behavior Change (HIPs 2018) considers the use of digital media for FP programs a promising practice. The brief summarizes a total of 11 studies which looked at more general sexual and reproductive health outcomes as well as contraceptive use. Of the six studies that assessed the impact of exposure to digital health applications on SRH knowledge, five demonstrated a positive effect, including improved knowledge about various contraceptive methods and related side effects, fertility, menstruation, and locations of health facilities or where to get condoms. Five studies found improved attitudes and beliefs related to contraceptive methods, which included dispelled myths and misconceptions, alleviated concerns about the safety and risks, more positive perceptions about ease of use generally as well as specifically related to condom use. Four of the studies assessed self-efficacy, including participants' ability to both discuss and use condoms and other contraception with their partner. These studies showed positive outcomes around FP interventions, especially those aimed at young people. In particular, the review specifically noted that "digital technologies may offer more options to reach young people," especially since young people's use of digital technologies is rapidly increasing. As will be further described, digital technology not only allows for additional confidentiality, privacy, and anonymity, which are important for many young people, but also has the ability to deliver information to individuals in any place and at any time.
The five studies that evaluated changes in contraceptive behavior found significant increases in modern contraceptive use, at least in the short term, in four of the countries, although the type of digital technology used differed considerably between them. The Digital Health HIP describes how, in Cambodia, women received short message service (SMS), commonly referred to as text messages, about modern contraceptives for three months after they had undergone an abortion (Smith et al. 2016). The study found that intervention group women were more likely than the control group to report contraceptive use after four months (64 percent versus 46 percent, respectively; relative risk: 1.39). However, these differences were not statistically significant after 12 months. In addition, when analyzing repeat pregnancies or abortions at 4 and 12 months, there were no significant differences between the groups. In Nigeria, where participants received prerecorded calls and SMS reminders, modern contraceptive use in the intervention group increased significantly (from 23 percent to 37 percent) while in the control group it remained nearly the same (at about 21 percent) (Babalola et al. 2017).

Studies with statistically insignificant findings cited problems with the technology-network failure, platform adaptability, or lengthy periods of short-code failurewhich likely impeded programmatic impact (Babalola et al. 2017; Ashcroft et al. 2017).

The widely differing technologies used in the studies reviewed in the HIP brief comprised SMS messages, voice calls, and pre-recorded calls. None considered the use of social media such as Facebook or apps such as WhatsApp, which are becoming increasingly popular among young people both for FP messaging and information-sharing in daily life. This points to the need for more standardized definitions of what is considered digital media in such research and for the inclusion of social media. In addition, none of the studies reviewed in the HIP related specifically to the impact of digital technology on young people's FP knowledge and use. However, an SMS-based intervention in Kenya that asked its participants, all under age 20, about the effect of the intervention, found that nearly two-thirds reported positive changes in FP and contraceptive use, including using dual protection and modern methods such as intrauterine devices and pills (Vahdat et al. 2013).

The 10 articles selected by the HC3 data base when filtered by "new media" comprised a combination of studies (including the post-abortion FP intervention in 
Cambodia described above), some of which used hotlines or phone calls from providers. Only two used social media combined with other phone-based approaches or inter-personal communication, such as an intervention in Kenya designed to increase comprehensive reproductive health, FP, and HIV prevention service usage among married adolescent girls (Undie et al. 2014). The initiative included an interactive media campaign, community health worker training, and the distribution of reproductive health, FP, and HIV information, education, and communication materials. Specific program activities included a new radio soap opera, accompanied by leaflets and posters, a weekly discussion, and a Facebook page. In addition, community health workers were trained to do home visits and referrals. The intervention evaluated FP incidence over time among married girls aged 14-19 years. At baseline, 38 percent of married adolescent girls were using an FP method, including the injectable (66 percent), condoms (13 percent), and the pill and standard days method (both at 9 percent). After the intervention, 46 percent of married adolescent girls were using a FP method, which was a significant increase. However, the evaluation appeared unable to disaggregate the impact of digital media elements of the program from other aspects of the intervention.

Mobile phone interventions around FP appear to be better documented than those using social media. In a substantive review, McCarthy et al. (2018) note that trials have provided some evidence that interventions delivered by mobile phone can improve contraceptive-related behaviors (Berenson and Rahman 2012; Trent, Thompson, and Tomaszewski 2015) and knowledge (Hall, Westhoff, and Castano 2013; Johnson et al. 2017). However, others have failed to find an effect (Kirby et al. 2010; Bull et al. 2016).

In addition, the authors note the lack of high-quality efficacy studies evaluating such interventions in LMICs. They supplemented a 2015 Cochrane Review of five trials (Smith et al. 2015) with an additional search revealing 11 trials (eight SMS, two apps, and one voice message intervention), of which four were conducted in LMICs. Importantly, it was noted that the content of four interventions was developed through iterative consultation with the target groups. Of the five trials where FP knowledge was an outcome, four showed a beneficial effect of the intervention compared to the control group.

McCarthy et al. (2018) then describe an initiative coordinated by the London School of Hygiene and Tropical
Medicine and Member Associations of the International Planned Parenthood Federation in Tajikistan, Bolivia, and Palestine. In each country, an intervention aimed at young people under age 24 delivered by mobile phone aimed to improve their attitudes toward effective contraceptive methods. Upon evaluation, the most robust findings occurred in Palestine where young people were more likely to find the intrauterine device, injection, implant, patch, and long-acting reversible contraceptive methods acceptable. The intervention sent by SMS increased knowledge of, acceptability of, and intention to use effective contraception and changed perceived norms in relation to use compared to the control SMS about trial participation. In addition, perceived norms in relation to the acceptability of friends using effective contraception were generated.

THE RATE AT WHICH MOBILE PHONE TECHNOLOGIES AND SOCIAL MEDIA ARE BEING ADOPTED MAY OUTPACE THE RATE OF EVALUATION.

In conclusion, there is a paucity of studies on the impact of digital health innovations on FP in LMICs. Those which do exist are sometimes of poor methodological quality, do not standardize definitions of "digital media" nor routinely include social media, and few have robustly evaluated impacts on patient outcomes (Lee et al. 2016; Forrest et al. 2015) emphasize how rigorous studies with potential to offer clearer evidence are needed. The rate at which mobile phone technologies and social media are being adopted may outpace the rate of evaluation. Importantly, they note that other methods of evaluation should be considered beyond only randomized controlled trials. In addition, there is also a need for more qualitative research in order to better understand the processes of behavior change related to digital media and digital technologies. Such approaches might explore the kinds of messaging or content considered acceptable and the social context of use. These could contribute to a revised behavior change model in order to have a better understanding of young people's decision-making in the context of their often considerable online presence. This is further discussed in "Potential need..." section (pg 25). 


\section{Summary of evidence and gaps}

TABLE 1 SUMMARY OF EVIDENCE AND GAPS FROM EVALUATED STUDIES ON MASS MEDIA, DIGITAL MEDIA, AND FP

\section{MASS MEDIA EVIDENCE}

Shown to have proven impact

Over 30 years of data; Large number of studies (especially RCTS)

Effective at improving FP attitudes and uptake (although evidence related specifically to its effectiveness with youth is lacking)

Shown to be cheap and highly cost-effective

Dose-response effect

More likely to reach higher wealth quintiles in urban areas

Appears to improve interpersonal/spousal communication in selected settings

Print media ineffective possibly due to high levels of female illiteracy

Best used as complementary approach in tandem with improved service provision and outreach.

Likely to impact on FP through modifying ideation and proximate factors such as gender equity

Appears to reduce social inequalities in acquisition of health information

MASS MEDIA GAPS AND CHALLENGES

In RCTs, difficult to randomly assign participants to treatment arm of study given

universality of mass media

Impact specifically on youth often not evaluated

Difficult to tease apart effects in interventions comprising multiple communication

channels including interpersonal communication and outreach

Difficult to distinguish independent effect of mass media from factors (such as inter-

personal communication) which create an "enabling environment"

Evaluations are often limited to indicators focusing on reported or intended, rather than observed, behavior

Needs concurrent supportive policies to maximize impact

SOCIAL / DIGITAL MEDIA

Shown to have promising impact

Highly appealing to young people

Facilitates confidentiality of knowledge acquisition and sharing

$<10$ years of data; Small number of studies

Some evidence of impact on attitudes and uptake (at least in short term)

Effective at dispelling myths and rumors

Need to ensure network function, platform adaptability, and message quality

\section{SOURCE}

HIPs (HIPs 2017)

HC3 FP Evidence Database

HIPs (HIPs 2017)

HIPs (HIPs 2017)

Nigeria URHI (2014)

Suranwanshi et al. (2016)

Babalola, Figueroa, and Krenn (2017)

Souguo et al. (2017)

Wakefield, Loken, and Hornik (2010)

Krenn et al. (2014)

Lin et al. (2014)

\section{SOURCE}

Kasteng et al. (2018)

HIPs (2014)

HIPs (2014)

HIPs (2014)

Naugle and Hornik (2014)

Whittaker, McRobbie, and Bullen (2016)

\section{SOURCE}

HIPs (HIPs 2018)

HIPs (HIPs 2018)

HIPs (HIPs 2018)

HC3 FP Evidence Database

Trent, Thompson, and Tomaszewski (2015)

McCarthy et al. (2018)

Babalola et al. 2017, Ashcroft et al. 2017 
SOCIAL / DIGITAL MEDIA GAPS AND CHALLENGES

Overreliance on RCTs or studies of poor methodological quality

Field expanding incredibly quickly and research unable to keep up

Definitions of what constitutes digital media are inconsistent across studies

Programs using digital media approaches tend to be small and ad hoc and need to be scaled-up

Need for further studies (non RCTs) and qualitative research to understand processes

of impact

Need to better understand the process of attitudinal and behavior change attributable to digital media

\section{SOURCE}

Forrest et al. (2015)

HC3 FP Evidence Database

Guse et al. (2012)

Etrilabs, personal communication 2019

Johnson, Juras, and Riley (2017)

Etrilabs, personal communication (2019) 


\section{Cost effectiveness of mass media and digital media programs}

Hutchinson and Wheeler (2006) reviewed a number of health communication programs globally and concluded that first, analysis of the cost-effectiveness of such programs occurs infrequently. Second, the studies that did assess cost-effectiveness did not use consistent methodologies and had varying levels of quality, which creates problems around transparency, comparability, and generalizability.

A database search on FP studies worldwide where cost-effectiveness featured in the title or key words was helpfully carried out by Avenir Health for the purposes of this literature review. It found 27 studies, the vast majority of which were between 10 and 20 years old. They included, for example, a study by Kincaid and Do (2006) in the Philippines which found that a national mass media campaign, including its direct and indirect effects on attitudes about FP, led to a 6 percentage point

EACH PROGRAMMATIC

ELEMENT IS LIKELY TO HAVE

DIFFERENT COST-EFFECTIVENESS

IMPLICATIONS AND FUTURE

EVALUATIONS SHOULD TAKE THIS

INTO ACCOUNT AND EVALUATE

THE INDIVIDUAL AND COMBINED

CONTRIBUTIONS OF EACH

PROGRAMMATIC COMPONENT.
Congo documented the target population reached and audience size, as well as costs per listener (CPL) and cost per behavior change. There was significant inter-country variation in the cost per behavior change. For example, "Frequent spousal discussion of family planning" cost only US\$1.76 per adopter in Burundi but US\$4.73 in Rwanda; "Visited health institution to get information on family planning side effects" cost US\$2.73 per adopter in Burundi compared with US\$25.37 in the Democratic Republic of Congo.

As described, there are only a few studies of the cost-effectiveness of mass media campaigns around FP, but additional analyses have been carried out with regard to other aspects of maternal and child health. For example, in Bangladesh, the Smiling Sun campaign used a television drama as well as radio, newspaper, and billboards to improve antenatal care and immunization rates.

Using national-level data, Hutchinson et al. (2006) found that the campaign was effective for both behaviors and cost, leading to higher levels of service utilization for only $\$ 0.05$ per additional antenatal care user and only $\$ 0.30$ and $\$ 0.36$ for each additional child vaccinated for measles and diphtheria, pertussis (whooping cough), and tetanus (DPT3), respectively. The cost per attributable behavior change based on local promotion activities was considerably higher-nearly $\$ 37$ per new DPT3 vaccination, $\$ 32$ per new measles vaccination, and $\$ 8$ per new antenatal care user.

In rural Burkina Faso, Kasteng et al. (2018) collected provider cost data alongside a 35-month cluster randomized trial from 2012 to 2015 to explore the impact of a number of elements of a maternal and child health program. The campaign broadcast 74,480 radio spots and 4,610 2-hour shows through seven local radio stations, reaching approximately 2.4 million people, including 620,000 pregnant women and children under five. As a result, there was an estimated 24 percent increase in care seeking for children under five and a 7 percent reduction in child mortality per year. Based on the increased care-seeking behavior and its effects on child survival, the study team estimated the intervention's incremental cost- 
effectiveness ratio (ICER) in terms of the cost per disability-adjusted life year (DALY) averted versus the baseline figures. The provider cost of the campaign was $\$ 7,749,128$, increasing to $\$ 9,146,101$ with household costs included. The ICER was estimated at \$94 (\$111 including household costs). The authors then projected the ICER for national-scale implementation of different media structures in five sub-Saharan African countries. The projected provider cost per DALY averted with a national campaign in Burkina Faso, Burundi, Malawi, Mozambique, and Niger in 2018-2020 varied from $\$ 7$ in Malawi to \$27 in Burundi. It was concluded that mass-media campaigns can be very cost-effective in improving child survival in areas with high media penetration, especially when taking advantage of economies of scale.

It should be noted that a similar trial has recently been completed in Burkina Faso and relates specifically to FP'14. This is the first RCT to specifically test the effectiveness of a FP mass media campaign. It was implemented from May 2016 to December 2018 on eight radio stations across the country and in eight control zones. Its goal was to increase the usage of modern contraceptive methods. The intervention included 10 one-minute radio spots per station and two regular phone-in radio shows. It was estimated to reach 3.5 million people and the final results pertaining to its impact and cost-effectiveness will be published in late 2019.

In Ghana, from 2013 the MOTECH (Mobile Technology for Community Health in Ghana) intervention used digital technologies including a series of voice messaging to improve the health of pregnant women and those post-partum (LeFevre et al. 2017). Frontline health workers can use the "Client Data Application" to digitize service delivery information and track patient care. MOTECH's other main element, the "Mobile Midwife," sends automated educational voice messages to pregnant and postpartum women's mobile phones. The authors examined potential scale up of MOTECH over a 10-year period and its estimated costs and consequences. Costs were calculated from informant interviews and financial records. The Lives Saved Tool helped model health effects using data from an independent evaluation of changes in key services coverage observed in Gomoa West District. Incremental costeffectiveness ratios were presented for each

${ }^{14} \mathrm{https}: / /$ www.developmentmedia.net/burkina-faso-family-planning-rct. html

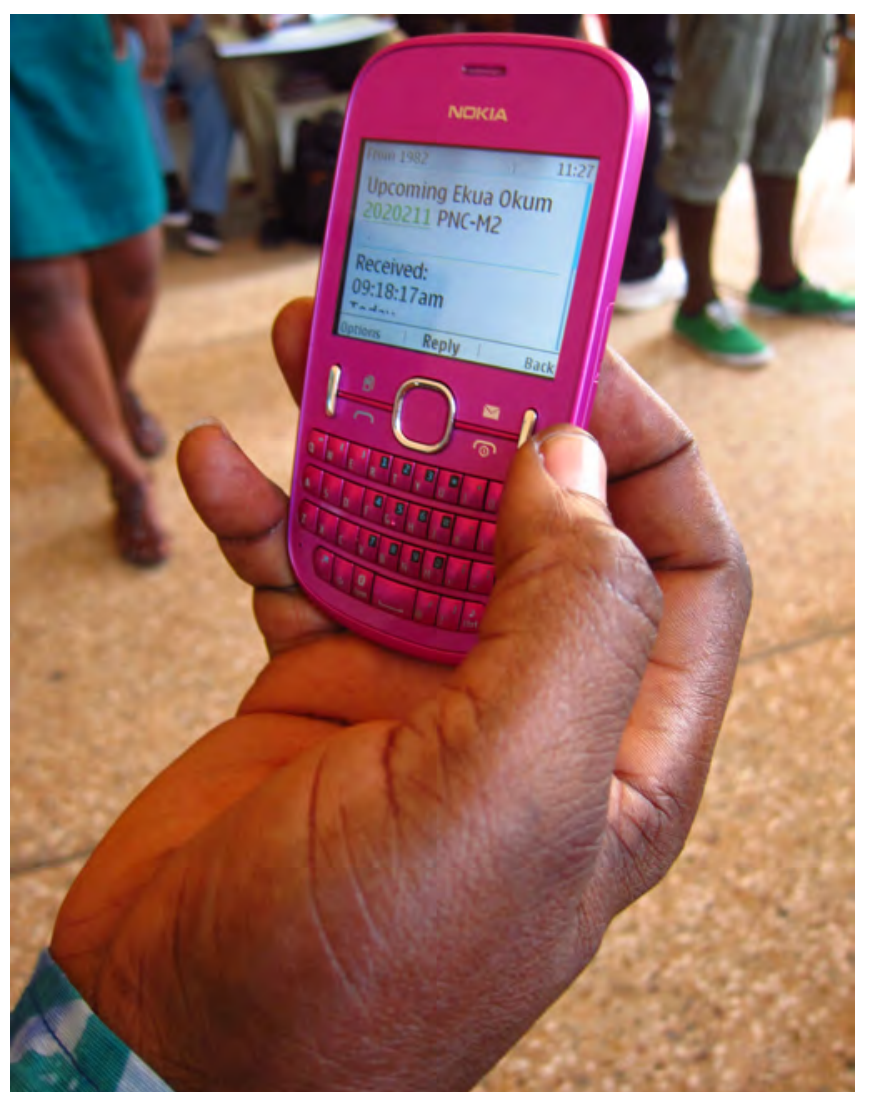

Photo Credit: @2013 Francis Gonzales, Courtesy of Photoshare

implementation year as well as overall. Over a three-year scaling period, MOTECH was able to reach 79 percent $(170 / 216)$ of Ghana's districts. It was calculated that on average, program sustainability would cost each district US\$17,618 annually. Over 10 years, this computes to an estimated 59,906 potential lives saved at a total cost of US\$32 million. The incremental cost per DALY averted ranged from US\$174 in the first year to US\$6.54 in the 10th year of implementation, or US\$20.94 (95 percent $\mathrm{CI}$ US\$20.34-\$21.55) on average over 10 years. Probabilistic sensitivity analyses suggested that with a willingness-to-pay threshold of US\$50, MOTECH had a 100 percent probability of being cost-effective.

It is noticeable that, like the behavior change studies, those assessing cost-effectiveness tend not to separate multiple programmatic elements (for example, as discussed above a number of interventions combine mass media and digital media as well as interpersonal communication, outreach, and strengthened service delivery). Each element is likely to have different cost-effectiveness implications and it is recommended that future evaluations take this into account and evaluate the individual and combined contributions of each programmatic component. 


\section{Specific lessons learned from selected mass media and digital media initiatives to improve FP behaviors among young people}

This section highlights specific elements of mass media and digital media campaigns which appear to have contributed to improved impact in relation to SRH/FP behavior change in a number of West African settings (and elsewhere if relevant ${ }^{15}$. It is distinct from the previous section, "Mass media and digital technology in sub-Saharan Africa" (page 7), which only presents studies that use robust methods such as RCTs to show impact on health and FP attitudes and behaviors. Here, the aim is to understand some of the processes of potential change in relation to mass media, digital media, FP, and youth. The review therefore includes qualitative or anecdotal information from projects which, although they show promise, may not have been rigorously evaluated. The discussion isolates specific elements of communication messages, their methods of diffusion, together with their possible pathways of influence on FP uptake.

Annex 1 summarizes a selection of project approaches linked to specific communication initiatives and, if available, their evaluation methods, impact, and lessons learned. It should be noted that this is not an exhaustive list of interventions but rather ones that are widely known to have achieved impact (for example, MTV's Shuga in Nigeria) as well as those that show promise for young people in the OP countries, for example, Les Jeunes Ambassadeurs de la PF and the "C'est la Vie" (CLV) television show ${ }^{16}$.

\footnotetext{
${ }^{15}$ Most of the selected initiatives focus on behavior change in relation to FP among men and women of reproductive age-very few identified initiatives focus upon youth. However, it is likely that some of the lessons learned are applicable to communication strategies aimed at young people.

${ }^{16}$ As described above, Les Jeunes Ambassadeurs are young activists who promote FP among their peers through a variety of communication and advocacy activities often using social media. C'est La Vie is a television series conceptualised with, and initially aimed at, young people in Senegal
}

The sub-sections below will not describe the different initiatives in detail, except for les Jeunes Ambassadeurs and CLV which are highly relevant to the OP country contexts. Additional project specifics are available in the Annex.

\section{Mass media}

\section{Multiple media platforms}

The distinction between projects that use "mass media" and "social/digital media" is misleading. Annex 1 shows that many interventions use multiple media platforms concurrently along with community-based activities such as outreach. For example, "You Only Live Once" (YOLO), a television series in Ghana aimed at young people, also developed a significant digital media presence. Simultaneously, it expanded the broadcasts to include a participatory studio-based chat-show called "YOLO Hangout" while also carrying out community sensitization sessions around the episodes' content and organizing radio phone-ins (YOLO project reports 2017, 2018). Unfortunately, as is the case with many media-based interventions, there appears to be no evaluation of the impact of YOLO's individual or collective platforms on health and FP-related behavior, which points to a need for improved research in this area.

\section{Gender equity}

Annex 1 shows that many of the selected radio and television initiatives described had an important gender-equity component. In cases where evaluations were robust and rigorous, these appear to have resulted in improved gender relations, FP attitudes, and knowledge among

\footnotetext{
but now screened more widely in Francophone Africa. Elements of the series are diffused via digital media and also used in community sensitisation and outreach activities.
} 
men. In Nigeria, being exposed to the television series Shuga resulted in less gender-based violence and forced sexual encounters (World Bank 2016). In Benin, Tékponon Jikuagou's radio slots, combined with other community-based interventions resulted, in some cases, in a greater impact on men than women (Annex 1). Women who heard Tékponon Jikuagou radio were 1.5 times more likely than other women to talk with their spouse about the number of children they should have, and 1.6 times more likely to talk about which FP method to use. However, men who had been exposed to the project's messages on the radio were over twice as likely to talk with their spouse about what FP method to use and how to obtain the method than unexposed men (IRH 2018). Thus, it is possible that media messages that address gender relations as a means to improving FP behaviors are likely to be more successful than those that do not. Further research is needed to establish whether gender equity is a necessary condition in order to achieve impact with regard to FP communication programming.

\section{Community outreach}

In addition, the successful mass media initiatives seemed to have core elements of community outreach and interpersonal communication. For example, in Uganda, the radio initiative "Oteka" attributed some of its success to its use of the Community Action Cycle (IRH 2017). This engages community leaders in a process of analyzing, acting for, and fostering ownership of community change. Oteka worked with civil society including the Concerned Parents Association and Straight Talk Foundation to set up resource centers and partnered with existing community groups rather than forming project-specific groups. This reduced resource investments and had the further benefit of building trust between staff and communities.

\section{Youth participation}

Many of the well-documented mass media initiatives presented in Annex 1 have considerable youth input into their content and storylines. Probably one of the most participatory initiatives is the "C'est la Vie" television show conceptualized in Senegal but diffused more widely throughout the region. The scripts for each episode are developed in a participatory manner with the young audience and tested among a select group of young people before they are filmed (RAES M and E Officer, Personal communication 2019). Audience reaction is ascertained not only from the discussion sessions which occur before filming, but also once the episodes have been aired on television and diffused via social media.
Community-based "Ratangu" clubs in six counties also give feedback and, among other mechanisms, Facebook comments on the themes and plots are taken into account for the development of subsequent episodes. This ensures that the narratives are relevant to young people's realities and are likely to create a sense of ownership among youth.

\section{Digital media}

\section{Content and purpose of digital media}

As the field is relatively new, one of the main problems is that there is a shortage of high-quality content in relation to FP and youth that can be diffused via digital media channels (Senam beheton, Etrilabs, personal communication, 2019). For example, in Mali, when the Jeunes Ambassadeurs were first recruited, they did not have very high educational levels and were not used to developing promotional texts that appealed to their peers. However, with training, they have improved and now independently develop and update content (Moctar Diallo, OP/Intrahealth, personal communication).

FURTHER RESEARCH IS NEEDED

TO ESTABLISH WHETHER

GENDER EQUITY IS A NECESSARY

CONDITION IN ORDER TO ACHIEVE

IMPACT IN FP COMMUNICATION

PROGRAMMING.
The feel and content of FP messages aimed at youth is key to their success, and evidence from outside Africa ${ }^{17}$ suggests that these need to be culturally framed and developed in a participatory manner. For example, a study of youth and FP messaging in Tajikistan, Bolivia and Palestine presented in Annex 1 noted that the type of acceptable and effective content differed depending on country context (McCarthy et al. 2018). Youth in Tajikistan wanted text messages that clarified how the

\footnotetext{
${ }^{17}$ This multi-country study in Tajikistan, Palestine, and Bolivia is cited here as little similar evidence about characteristics of SMS message content and family planning is available form African contexts.
} 
methods work as well as reassured them that they were safe to use. They also wanted the messages to be more "interesting and joyful." In Palestine, young people preferred messages that were "scientific" and gave feedback that some messages sounded too negative, so they suggested rewording them to sound more reassuring. In Bolivia, messages needed to be more light-hearted and contain emojis and endorsements from pop stars. The implementers incorporated feedback after each round of testing, revised them with the local partners and youth groups, and sent an updated set of messages in the following round.

The problem of a lack of content can also be addressed by using the same content on multiple platforms; content that infuses digital media, such as that viewed on phones or social networks, can be taken from television and radio. For example, in Francophone Africa, C'est La Vie, uses clips from the television show on their Facebook page and other on apps. This reinforces the messages via multiple sources and is likely to contribute to the dose response likely to be needed for behavior change.

The Jeunes Ambassadeurs are of particular interest in order to understand how the synergies of message content and platform contribute to the apparent (but as yet undocumented) success of their awareness raising activities. In tandem with their other activities (which include roundtables, a regional camp, and work with community leaders), the Jeunes Ambassadeurs use digital media for three distinct purposes across the OP countries:

1. To diffuse specific FP messages and accurate information and promote discussion

For example in Mali, the Jeunes Ambassadeurs did a campaign in February about "St Valentine's day without unintended pregnancy." In Togo, they promoted "Safestval" to campaign against unwanted pregnancy

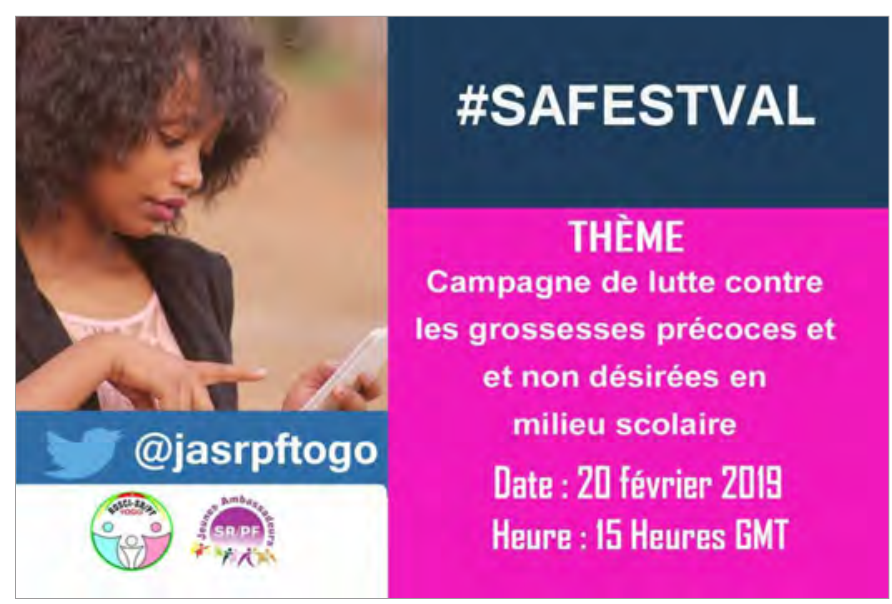

among school pupils. In Guinea, a WhatsApp group sends out daily messages (which are moderated) and promotes a group chat about FP for interested youth. Discussions with the actors in the field noted the importance of online, real time moderation and of verifying content to ensure it is accurate. This is especially important in these contexts, where, as noted above, myths and rumors about FP abound. The role of the internet in circulating misinformation is discussed in further detail in Section 9.0.

\section{To boost or promote a specific demand-creation activity}

For example, in Mali the cultural Festival sur le Niger attracts thousands of people from the town of Segou and nearby villages. For the February 2019 edition, the Jeunes Ambassadeurs worked with USAID-funded Keneya Jemu Kan (KJK) to create a 'Twitterthon' in order to provide information on FP, while mobile services were available on the festival site. The demand was so great that the mobile services had to prolong their stay beyond the duration of the festival (KJK manager, personal communication, 2019). Communication activities must ensure that services can meet increased demand creation. This is important, as research from elsewhere suggests that stockouts may especially affect young people as they often do not have the time, money, or autonomy to seek alternative supply sources and could quickly become discouraged about using a FP method at all (Castle 2016).

\section{For advocacy}

For example, the Jeunes Ambassadeurs in Burkina Faso recently publicized on their Facebook page how they had attended the Francophone African summit for social and behavior change in Abidjan. They shared their experience with delegates about how they had participated in the development of the country's costed implementation plan and how 30 percent of the plan's activities related to youth. In certain instances, such advocacy activities have led to cost-sharing and investment in the Jeunes Ambassadeurs' program by other donors, such as UNFPA (Moctar Diallo, OP/Intrahealth, personal communication 2019).

Annex 1 also documents online activity analyzed by KJK in Mali around its Facebook page. The project recognized that the lack of availability of FP content was problematic and it was suggested that this could be addressed by creating a bank of images and other support materials 
such as flyers. Their project report (KJK 2018) also noted that the spread of online rumors about FP on their FB page was also problematic and strategies need to be put in place to manage this. As emphasized above, this underscores the importance of real-time monitoring of digital media where posts may be negative or comprise inaccurate information that can then be circulated.

It should be noted that in many West African settings, high quality and reliable connectivity may be problematic and impede programs' effectiveness. In Ghana, the MOTECH initiative aimed at pregnant women noted it cannot always be assumed that digital health programs are performing as intended (LeFevre et al. 2017). For example, MOTECH's technological limitations distributing voice messages highlights the need for more low tech data to mitigate delivery challenges and improve exposure to health information in places that experience technical issues. The authors note that alternative message delivery (for example, SMS messages) could increase the reach of the campaign but might not be appropriate for illiterate users.

\section{Monitoring digital media activity}

An advantage of mobile phone messaging and other digital media is that communication and promotional activities can be tracked. This can occur at a basic level with Facebook analytics or through sites such as Statista ${ }^{18}$ which are more costly ${ }^{19}$.

\footnotetext{
${ }^{18}$ https://www.statista.com/

${ }^{19}$ It should be noted that mobile phone platforms also enable the collection of personal data, including mobile phone numbers from those who use the medium. This has very important implications for confidentiality (especially in settings where phone-sharing is common) and consent which need to be addressed within an appropriate ethical context. In Tanzania, PSI's strategy of "Connecting with Sara" (their client prototype) ensures consent through a series of robust procedures. Once these are completed, health workers use clients' mobile phones to diffuse messages aimed at preventing contraceptive discontinuation and to ascertain client
}

Both C'est la Vie and YOLO track digital media activity that runs parallel to the television shows. For CLV, project reports from August to December 2018 show that a total of 688,326 people were involved with the various platforms such as Facebook, YouTube, Twitter, and Instagram. Nearly three-quarters (74 percent) were engaged by Facebook, which was the most popular digital platform, followed by 12 percent via YouTube, 13 percent via Instagram, and one percent via Twitter. However, it was found that even though the number of views may be high, often they did not catalyze any comments or reactions. CLV's Q4 report noted that an online video seen by 12,000 people can have no commentary and fewer than 20 likes and shares, thus limiting its impact and cost-effectiveness.

YOLO digital media accounts (Facebook, Instagram, and Twitter) were active during the last year of the initiative (Table 2) and seemed to promote more online dialogue than CLV. The YOLO Facebook page has been particularly popular and engages followers on issues raised in each episode. It has received hundreds of comments including personal questions on adolescent reproductive health. Since late June, it has updated followers on planned and upcoming events like the Adolescent Reproductive Health Week celebrations in Ghana and in-school outreach activities. Questions were also posed each week to fans on a variety of online platforms-those who answered correctly were recognized in various ways, such as being the "most active Facebook friend." Other activities included quiz sessions moderated by a cast member on Facebook Live, with various prizes including YOLO T-shirts.

In addition, weekly episodes of YOLO were posted on YouTube. Subscriptions to the official YOLO channel

satisfaction (https://www.psi.org/publication/connecting-with-sara-harvesting-technological-innovation-to-re-imagine-healthcare/).

\section{TABLE 2 DIGITAL MEDIA ACTIVITY AROUND SERIES 3 AND 4 OF YOLO (2017-18)}

\begin{tabular}{|lcr|}
\hline DIGITAL MEDIA CHANNEL & SEASON 3 & SEASON 4 \\
\hline Facebook: Yologhana (likes) & 200,000 & 215,000 \\
Twitter (followers) & 12,143 & 16,900 \\
Instagram (followers) & 115,000 & 145,000 \\
\hline
\end{tabular}

Source: YOLO Project reports 2017-2018 
increased from 35,000 in Season 3 to 37,600 in Season 4. In Season 4 alone, YOLO received more than six million views on YouTube.

The 2016 digital media report from KJK in Mali, which seeks to generate demand for FP and $\mathrm{MCH}$ services, concludes that over 90 percent of the likes for their Facebook page came from residents in Bamako. Forty percent were men aged 18-24 and 13 percent were young women in this age group, highlighting that such approaches probably tend to attract males in major urban areas with good connectively and high levels of phone ownership. Such individuals are likely to already have fairly good knowledge of FP, and perhaps even use it, which raises issues of cost-effectiveness and duplication of effort. The project noted that the addition of games with prizes (for example, motorbikes and mobile phones) linked to competition questions had an important impact on driving traffic to the sites.

Evidence from these West African initiatives points to the need to understand how the next step can be initiated so that likes and shares occur and eventually lead to behavior change. At the moment, it is unclear how activity on the various digital channels leads to changes in FP attitudes and uptake, if at all, and, if changes do occur, whether they are solely due to digital media or to a combination of communication approaches. The projects that do monitor activity are still left with little or no information about the sociodemographic and economic characteristics of their followers and are thus unable to tailor FP messages to them.

Discussion with stakeholders such as Etrilabs and CS4FP hypothesized that a primary reason for the lack of robust analyses and the poor knowledge of the client base and users of such projects may be that such digital media initiatives are often youth-run and, quite rightly, place great emphasis on youth participation and management. However, such young people are likely to lack experience in monitoring and be unaware of the statistical requirements of robust evaluation. Nevertheless, it may be possible to encourage and support some limited pre-and post- intervention survey work, possibly with local research partners, for example, at universities. As described above, it is important to not necessarily insist on RCTs in the face of weak capacity and limited resources. Alternatively, young actors can also be encouraged to carry out qualitative exploration of the processes of change and potential impact.

\section{TABLE 3 SUMMARY OF LESSONS LEARNED IN RELATION TO MASS MEDIA, DIGITAL MEDIA, AND FP}

\section{MESSAGE CONTENT AND DIFFUSION}

Most programs have multiple forms of communication (often combined with community outreach), and evaluations find it difficult to tease apart the relative impact of each.

Communication messages focusing on gender equity may be a necessary condition for improving FP uptake.

Messages engaging men appear to improve attitudes, couple communication, and FP use among women.

Parallel community sensitization activities are likely to work better and be more cost-effective if they partner with existing organizations rather than creating new ones.

The real-time strategic management of FP myths and rumors posted on digital media is essential.

Backup strategies may be needed (e.g., SMS) in case of poor connectivity and low band width precluding voice or picture messages.

It is important to have youth participation in message content development through iterative pre-testing with youth stakeholders.

\section{EVALUATION}

Digital media has multiple roles (diffusing information, publicizing events/activities, advocacy) which require different evaluation approaches.

Digital media programs are, in general, not evaluated well or at all, possibly because the implementers are often young and relatively untrained in monitoring and evaluation.

Digital media initiatives often count hits, views, and likes, but this is insufficient to ascertain their impact on FP knowledge and behavior change.

The profiles of digital media users are poorly understood and this hampers audience segmentation for improved message targeting.

Mass media and digital media appears to be most used by those who are in urban areas and in higher wealth quintiles. These individuals are more likely to already know about FP and to potentially use it, leading to questions of cost-effectiveness and duplication of effort.

Note: Mass media and digital media are not separated here as many of the issues apply to both 


\section{Potential need for an adapted behavior change model to accommodate young people's online presence and interactions}

As presented previously, the evidence is often not very robust in terms of showing the impact of digital media (especially social media) on young people's FP knowledge and behavior, it is not yet well understood how behavior change occurs (if indeed it does) due to the use of digital technologies. It is suggested here that conventional behavior change models pertaining to FP may potentially not be appropriate for identifying the processes which drive uptake in settings where a lot of young people's FP information acquisition and exchange occurs online. It is documented elsewhere how online interactions, unlike face to face, can be anonymous, embolden rumors and misinformation, and present unverifiable or untrue testimonies (Chua and Banerjee 2015; Del Vicario et al. 2016). However, conversely, online interactions can also serve to spread correct information quickly as well as to create and efficiently share norms which could improve FP uptake (Ippoliti and L'Engle 2017). Social media thus presents a double edged sword for FP-on the one hand, it can improve knowledge and reinforce positive messages, but on the other, it can fuel myths and rumors that have been shown to be a major barrier to contraceptive use in much of Africa (Gueye et al. 2015; Wells 2015). Online FP initiatives are, to date, poorly understood apart from, as shown above, the routine monitoring of likes, views, shares, etc. If social and digital media are to progress from promising to proven practices for $\mathrm{FP}$, it is necessary to better understand who is using this medium and how any changes in FP knowledge and behavior can be a function of their digital presence, especially for young people.

It may be useful to revisit behavior change models that inform many FP programs, as they are frequently based around interpersonal communication, particularly in order to reach the stage of FP acceptance/approval and to convert it into "intention to use" a method. The specific role of digital media needs to be better acknowledged together with its role and place in the chain of events leading to uptake, especially in the context of multiple communication approaches.

The Shujazz initiative in Kenya notes how its social media platform helps potential users on their journey to having improved health behaviors (Hutchinson, Mirzoyants, and Leyton 2019). The initiative used the Transtheoretical Model (TTM) of behavior change, in which change unfolds over time, progressing through a series of stages, including pre-contemplation, contemplation, preparation, and action. During the pre-contemplation stage, the model indicates that individuals do not intend to act in the near future, either because they are uninformed, underinformed, or misinformed about the pros and cons

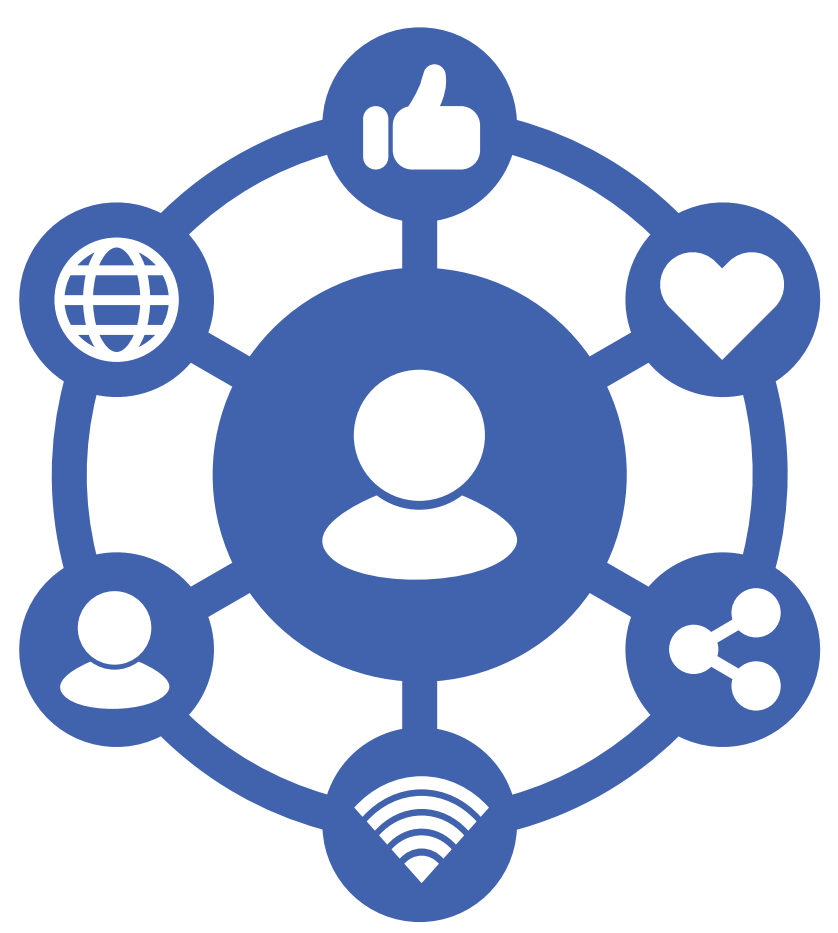


of specific behaviors (Glanz, Rimer, and Viswanath 2008). For participants in this stage, Shujaaz shares stories highlighting the relevance of proper planning around health-related issues. During the contemplation stage, youth may want or intend to change their behavior but focus instead on evaluating the merits and downfalls of their potential actions. At this stage, Shujaaz comic and radio stories dispel myths and misconceptions, while digital media conversations support youth discussion about available contraceptive methods. In the preparation stage, individuals are prepared to act and are already open to holding conversations with health providers, peers, parents, counselors, or other actors who could help them implement the desired action (Glanz et al. 2008). These interactions can happen on the Shujaaz social media platforms, on other platforms, or offline. Finally, individuals in the action stage are already taking specific steps toward the desired behavior change, including contraceptive use and recommending the use of sexual and reproductive health (SRH) services to peers, which they frequently do via digital and social media. Although the TTM appears to successfully underpin Shujaaz's activities, it was designed in the 1980s before social media became available. It is therefore unclear if the contemplation and preparation stages are subject to the same decision-making processes and validation if information is presented online and not necessarily via face-to-face contact. It is suggested here that further studies are needed to test the applicability of such a model in settings of high online information acquisition among young people.
MSI uses a FP behavior change model which comprises the following stages: Not aware $\rightarrow$ Aware-Know $\rightarrow$ Accept-Intend $\rightarrow$ Trial $\rightarrow$ Adoption $\rightarrow$ Advocate (MSI 2016). Field research in the Sahel using this model underscored the importance of interpersonal communication (including the real-life testimonies of successful and satisfied users) as well as peer and spousal support, which were found to be particularly effective in convincing those hesitating to adopt a method (Castle 2017). It may be that these behavioral models need to be adapted for young people who have a significant social media presence which places more importance on online influences and testimonies (regardless of accuracy) as opposed to real time, interactive, face-to-face contact. It is suggested that such models could be revised and tested in settings where digital media exerts a great influence on young people's decision-making and defines their world views. To date, it is unclear what an adapted behavior change model that accommodates online interactions would look like. However, there appears to be evidence from other domains that assesses, for example, the effect of anonymity and rumor-spreading as well as the advantages of creating online norms which lead to positive decision-making and outcomes (Liu and Baumeister 2016; De Ridder 2017). Lessons could be drawn from these and other studies for FP interventions that have a social media component to build a FP adoption behavior change model which better reflects young people's virtual influences and realities. 


\section{Conclusions}

This review has sought to document the impact of mass media and digital media on young people's FP attitudes and behaviors. Although both approaches are likely to contribute to behavior change, the impact of mass media is better documented and more widely accepted (by donors, governments, and implementers) as an impactful and cost-effective practice. By contrast, the importance of digital media (including social media) on contraceptive decision-making receives relatively scant attention in global discourse and little policy recognition (for example, in countries' national plans). It is used mainly at the program activity level in a rather ad hoc and unmonitored fashion. Much of the evidence as to its impact is, as yet, anecdotal, underscoring the need for more robust, objective evaluations of this communication channel which clearly has tremendous reach and potential among young people.

It is discussed above how the programmatic distinction between mass media and digital media is somewhat arbitrary, as many initiatives use multiple communication platforms (including outreach and interpersonal communication) in order to convey FP messages. Although there is robust evidence, documented over 30 years, as to the impact of mass media on health-related behavior in a number of domains, the impact of digital media (including social media) on FP behavior is less conclusive. For this reason, the review also included material from higher income countries where mass and digital media have been used in communication initiatives to prevent non-communicable diseases. It also drew on evidence from LMICs where such media had been used to create demand for services within campaigns around maternal and child health.

With regard to FP, mass media is classified as a "proven" practice within USAID's HIPs briefing series while digital media is designated as a "promising" practice. The examination of a selection of rigorously evaluated studies from mass media initiatives found that the majority had a number of other components such as social media and community sensitization. Evidence suggests that multi-pronged interventions involving multiple message channels are likely to enhance impact, notably through the phenomenon of a dose response. However, it is unclear from the studies reviewed how much of the increased uptake in modern contraceptive use can be attributed to mass media campaigns, as opposed to interpersonal communication, health system and service strengthening, and other activities aimed at increasing demand. It is also unclear how much mass media simply creates an enabling environment to facilitate uptake. In addition, as described above, further research is needed as to how such mass media campaigns specifically achieve impact among youth.

Digital media, and in particular social media, can be used to raise awareness about $\mathrm{FP}$, to promote specific events, and for advocacy. However, as described, the scale and sustainability of its impact on behavior is not well understood. This lack of robust evidence can be attributed to the relatively recent development of the channel as well as to the fact that such campaigns (for example, using WhatsApp or Facebook) are often youth-led and implemented. The evaluation of social media initiatives is also problematic for a variety of reasons, not least because of online platforms' protection of user data. In addition, although youth participation and leadership are very important for enhancing message acceptability, young people may not possess adequate evaluation skills. It is described how many projects simply measure online views, shares, or likes and do not realize the importance of knowing the demographic and socioeconomic characteristics of campaign followers in order to facilitate effective communication via audience segmentation. This is particularly relevant to adolescents who are such a diverse group and have different priorities with regard to their contraceptive needs and fertility expectations, for example, in relation to their marital and educational status and employment aspirations. There is therefore a need for the improved technical support of social media initiatives. This can serve to strengthen monitoring and evaluation to enable young people to robustly assess the impact of their digital and online activity. It is noted that such evaluations may need to move away from randomized controlled trials to, for example, pre- and post-intervention surveys. Qualitative research can be used to better understand the processes of change in attitudes and behavior catalyzed by online activity. Consistent digital media definitions and better audience identification and segmentation combined with robust monitoring and evaluation will improve knowledge about 
the impact of the channel on young people's FP decision making and make it more appealing to donors, governments, and implementers alike.

The review also notes that although many FP programs use behavior change models, such as the Transtheoretical Model of Behavior Change, these tend to place importance on interpersonal communication (for example, by satisfied users) as a means to persuade potential adopters. The dynamics of these interactions are significantly different from online exchanges which, on the one hand, can lead to the efficient sharing of viable information to generate demand, but on the other can potentially lead to the propagation of myths and rumors, which are the bane of FP programs in the region. It is suggested that the behavior change models may benefit from being revised to recognize young people's digital presence and the different nature of interpersonal interactions from those conducted online. Further research is needed to understand the role of digital media, and in particular, the way it influences behavior change both positively and negatively.

With regard to cost-effectiveness, evidence from health domains other than FP suggest that communication via mass media can be very cost-effective. For example, in Burkina Faso, radio campaigns were shown to significantly improve child survival and use of maternal and child health services and to benefit from considerable economies of scale. To date, there is little evidence as to the cost-effectiveness of digital media initiatives. It is of note that connectivity and mobile phone or computer usage is probably higher in urban areas and among educated cohorts. These individuals are more likely to use FP and this should be born in mind in order not to duplicate efforts with regard to promoting messages among a population which is probably already receptive to them.

In summary, the evidence suggests that, as part of multipronged initiatives, mass media and digital media have significant potential for improving knowledge, attitudes, and behavior with regard to FP communication programs among youth. However, to date, digital media appears to lack rigorous evidence of impact that could catalyze more investment by donors and stakeholders. Its enormous and rapidly increasing reach among young people in Africa and elsewhere urgently necessitates objective evaluations of its effect on attitudes and behavior in order for it to become a proven rather than a promising practice for FP programs. 


\section{Recommendations}

\section{MASS MEDIA AND DIGITAL MEDIA}

Ensure service provision (and service quality) can match demand creation.

CS4FP (2019)

Develop messages and content with young people in a participatory and iterative manner.

CS4FP (2019)

Acknowledge that messages aimed at men (especially via radio) appear to have an impact on their atti-

IRH (2017)

tudes toward FP and on uptake among women.

Build a sense of community ownership and improve cost-effectiveness by partnering existing organiza-

IRH (2017)

tions of stakeholders and beneficiaries during message development and diffusion.

\section{DIGITAL MEDIA}

Clarify definition of what constitutes digital media (e.g., mobile phone, SMS, social media, apps)

Know the audience and avoid duplication of effort-e.g., targeting of digital media users in higher income urban settings who are more likely to be FP acceptors.

Recognize that phone ownership and internet access is now reaching rural areas and content needs to be adapted for non-literate users (e.g., pictures and voice messaging).

Establish a content bank where information, videos, pictures, and messages can be stored and accessed for digital media campaigns

Encourage the cross-fertilization of media so that, for example, television and radio clips can be diffused via social media

Manage FP myths and rumors online through real-time monitoring to ensure that misinformation is not spread virtually.

Ensure back-up strategies (e.g., SMS messaging) are in place in situations of poor or intermittent connectivity.

\section{EVALUATION}

Ascertain impact of digital media FP interventions on FP as there are very few such studies to date.

Ascertain impact of mass/digital media FP interventions on youth as there are very few such studies to date.

Build more evidence encouraging a wider range of methodologies to better understand the processes of attitudinal and behavior change (especially due to social media).

Assess if behavior change models reflect young people's significant online presence and adapt if necessary to accommodate digital information acquisition and exchange into understanding their FP decision-making.

Incorporate cost-effectiveness measures into studies of communication interventions around youth and FP.

In multi-pronged projects, for example, those involving mass media, digital media, interpersonal com-

munication, and outreach, isolate their separate and combined contribution to the dose response to FP attitudes and uptake.

Identify the necessary conditions for FP behavior change, e.g., through ideational changes or via proximate determinants such as gender equity.

Ascertain observed FP behavior resulting from mass/digital media interventions rather than intent to use or reported behavior.

Empower young people to monitor and evaluate their digital media activities to promote efficacy and sense of agency as well as to objectively measure impact.

Enable young online activists to gain insights into followers' socioeconomic and demographic characteristics for improved targeting and segmentation.
HIPs (2018)

KJK-CCP Mali

Ertilabs (2019)

KJK-CCP Mali

Etrilabs (2019)

KJK-CCP Mali

LeFevre et al. (2017)

\section{HIPs (2018)}

HIPs 2014, HIPs 2018, HC3 FP Evidence Database

Forrest et al. (2015),

Hutchinson, Mirzoyants, and Leyton (2019)

Hutchinson and Wheeler (2006)

Babalola, Figueroa, \& Krenn (2017)

WHO (2010)

McCarthy et al. (2018)

Etrilabs (2019)

RAES (2019) 
Alam, Q., M. A. Yusuf, and K. Coghill. 2009. "Village phone program, commodification of mobile phone set and empowerment of women," Journal of Community Informatics 5(3-4).

Aluzimbi, G. et al. 2013. "Risk factors for unplanned sex among university students in Kampala, Uganda: a qualitative study," International Journal of Adolescence and Youth 18(3): 191-203. doi: 10.1080/02673843.2012.685947.

Ankomah, A. et al. 2014. "The effect of mass media campaign on the use of insecticide-treated bed nets among pregnant women in Nigeria," Malaria Research and Treatment 2014: 694863. doi: 10.1155/2014/694863.

Ankomah, A., J. Anyanti, and M. Oladosu. 2011. "Myths, misinformation, and communication about family planning and contraceptive use in Nigeria," Journal of Contraception 2: 95-105. doi: 10.2147/OAJC.S20921.

Ashcroft et al. 2017. "Implementation of CycleTelFamily Advice: an SMS-based service to provide family planning and fertility awareness information in India," Mhealth 3:20. doi: 10.21037/ mhealth.2017.05.01.

Babalola, S., M. E. Figueroa, \& S. Krenn. 2017. “Association of mass media communication with contraceptive use in sub-Saharan Africa: a meta-analysis of Demographic and Health Surveys," Journal of Health Communication 22(11): 885-895. doi: 10.1080/10810730.2017.1373874.

Babalola, S. et al. 2017a. "Evaluation of the effects of Smart Client Digital Health Tool in Kaduna, Nigeria. Report prepared for the Health Communication Capacity Collaborative (HC3)." http:// healthcommcapacity.org/wp-content/uploads/2017/10/ Evaluation-of-the-Effects-of-the-Smart-Client-Digital-HealthTool_FINAL-FINAL.pdf (Accessed 27 March 2019).

Berenson, A.B. and M. Rahman 2012. "A randomized controlled study of two educational interventions on adherence with oral contraceptives and condoms," Contraception 86(6):71624. doi: 10.1016/j.contraception.2012.06.007.

Blum, R.W. and K. Nelson-Nmari. 2004. "The health of young people in a global context," Journal of Adolescent Health 35(5):402-18. doi: 10.1080/00324728.2017.1291986.

Bongaarts, J., B.S. Mensch, and A.K. Blanc. 2017. "Trends in the age at reproductive transitions in the developing world: the role of education," Population Studies 71(2): 139-154.

Bove, R.M., E. Vala-Haynes, and C. Valeggia. 2014. "Polygyny and women's health in rural Mali," Journal of Biosocial Science 46(1): 66-89. doi: 10.1017/S0021932013000059.

Braun, R., C. Catalani, J. Wimbush, and D. Israelski. 2013. "Community health workers and mobile technology: a systematic review of the literature," PLOS ONE 8(6): e65772. doi: 10.1371/ journal.pone.0065772.

Bull, S. et al. 2016. "Text messaging, teen outreach program, and sexual health behavior: a cluster randomized trial," American Journal of Public Health 106(S1): S117-S124.
Castle, S. 2016. "Intersections between youth and reproductive health supplies: a report to the Reproductive Health Supplies Coalition Brussels." Brussels: Reproductive Health Supplies Coalition.

Castle, S. 2017. "MSI's youth strategy and programming for the Sahel: formative research findings from Senegal," a report to Marie Stopes International.

Castle, S. and I. Askew. 2016. "Contraceptive discontinuation: reasons, challenges, and solutions." New York: Population Council.

Chua, A.Y. and Banerjee, S. 2015. "Analyzing users' trust for online health rumors." In: Allen R., Hunter J., Zeng M. (eds) Digital Libraries: Providing Quality Information. ICADL 2015. Lecture Notes in Computer Science vol. 9469. Springer, Cham

Coleman, J. 2018. "Sawubona MAMA: Using mHealth to improve maternal, neonatal and child health outcomes in South Africa," PhD Thesis. Stockholm, Sweden: Karolinska Institutet.

Cookingham, L.M. and G.L. Ryan. 2015. "The impact of social media on the sexual and social wellness of adolescents," Journal of Pediatric and adolescent Gynecology 28(1): 2-5. doi: 10.1016/j.jpag.2014.03.001.

Curtis, A.C. 2015. "Defining adolescence," Journal of Adolescent and Family Health 7(2): 2.

Dallery, J., B. Jarvis, L. Marsch, and H. Xie. 2015. "Mechanisms of change associated with technology-based interventions for substance use," Drug and Alcohol Dependence 150: 14-23. doi: 10.1016/j.drugalcdep.2015.02.036.

De Ridder, S. 2017. "Social media and young people's sexualities: values, norms, and battlegrounds," Social Media and Society 3(4): 2056305117738992. doi: 10.1177/2056305117738992.

Del Vicario, M. et al. 2016. "The spreading of misinformation online," Proceedings of the National Academy of Sciences 113(3): 554-559. doi: 0.1073/pnas.1517441113.

Durkin, S., E. Brennan, and M. Wakefield. 2012. "Mass media campaigns to promote smoking cessation among adults: an integrative review," Tobacco Control 21(2): 127-138. doi: 10.1136/tobaccocontrol-2011-050345.

FP2020. 2019. Adolescents, youth and family planning. https:// www.familyplanning2020.org/ayfp (Accessed 27 March 2019).

Farley, T.A. 2015. "Mass diseases, mass exposures, and mass media," JAMA Internal Medicine, 175(11): 1743-1744. doi: 10.1001/jamainternmed.2015.5079.

Forrest, J. I. et al. 2015. "Mobile health applications for HIV prevention and care in Africa," Current Opinion in HIV and AIDS 10(6): 464-471. doi: 10.1097/COH.0000000000000198.

Glanz, K., B.K. Rimer, and K. Viswanath (eds.) 2015. Health Behavior: Theory, Research, and Practice. John Wiley \& Sons.

Groth, H. and J.F. May (eds.) 2017. Africa's Population: in search of a demographic dividend. Basel, Switzerland: Springer International Publishing. 
Gueye, A., I.S. Speizer, M. Corroon, and C.C. Okigbo. 2015. "Belief in family planning myths at the individual and community levels and modern contraceptive use in urban Africa," International Perspectives on Sexual and Reproductive Health 41(4): 191-199. doi: 10.1363/4119115.

Guse, K. et al. 2012. "Interventions using new digital media to improve adolescent sexual health: a systematic review," Journal of Adolescent Health 51(6): 535-543. doi: 10.1016/j. jadohealth.2012.03.014.

Hale, D.R. and R.M. Viner. 2018. "How adolescent health influences education and employment: investigating longitudinal associations and mechanisms," Journal of Epidemiology and Community Health 72(6): 465-470. doi: 10.1136/jech-2017209605.

Hall, K.S., C.L. Westhoff and P.M. Castano 2013. "The impact of an educational text message intervention on young urban women's knowledge of oral contraception," Contraception 87(4): 449-54. doi: 10.1016/j.contraception.2012.09.004.

High Impact Practices in Family Planning (HIPs). 2017. Mass media: reaching audiences far and wide with messages to support healthy reproductive behaviors. Washington, DC: USAID. Available from: https://www.fphighimpactpractices.org/ briefs/mass-media.

High-Impact Practices in Family Planning (HIPs). 2018. Digital health for social and behavior change: new technologies, new ways to reach people. Washington, DC: USAID. Available from: http://www.fphighimpactpractices.org/briefs/digital-health-sbc/.

Hutchinson, P. and J. Wheeler. 2006. "The cost-effectiveness of health communication programs: what do we know?," Journal of Health Communication 11(Supp2): 7-45.

Hutchinson, P. et al. 2006. "Measuring the cost-effectiveness of a national health communication program in rural Bangladesh," Journal of Health Communication 11(Supp2): 91-121.

Hutchinson, P., A. Mirzoyants, and A. Leyton. 2019. "Empowering youth for social change through the Shujaaz multimedia platform in Kenya," International Journal of Adolescence and Youth 24(1): 102-116. doi: 10.1080/02673843.2018.1475287.

Institute for Reproductive Health. 2017. "Gender roles, equality and transformations project: from pilot to scale." Washington, DC: Georgetown University.

Institute for Reproductive Health. 2018. "Tékponon Jikuagou," Final Report. Washington, DC: Georgetown University.

International Telecommunications Union. 2018. "Least developed countries on track to achieve SDG 9.c on universal and affordable Internet access by 2020" https://www.itu.int/en/mediacentre/Pages/2018-PR02.aspx (Accessed 27 March 2019).

Jah, F., S. Connolly, and W. Ryerson. 2018. "Comparing the cost-effectiveness of mass media long-running entertainment-education (EE) for social and behaviour change in Africa," The Journal of Development Communication 29(1): 61-72.

Johnson, D. et al. 2017. "A randomized controlled trial of the impact of a family planning mHealth service on knowledge and use of contraception," Contraception 95(1): 90-97. doi: 10.1016/j.contraception.2016.07.009.
Källander, K. et al. 2013. "Mobile health (mHealth) approaches and lessons for increased performance and retention of community health workers in low-and middle-income countries: a review," Journal of Medical Internet Research 15(1): e17. doi: 10.2196/jmir.2130.

Kasteng, F. et al. 2018. "Cost-effectiveness and economies of scale of a mass radio campaign to promote household life-saving practices in Burkina Faso," BMJ Global Health 3(4): e000809.

Kincaid, D.L. and M.P. Do. 2006. "Multivariate causal attribution and cost-effectiveness of a national mass media campaign in the Philippines," Journal of Health Communication 11(S2): 69-90.

Kirby D. et al. 2010. "Impact of an intervention to improve contraceptive use through follow-up phone calls to female adolescent clinic patients," Perspectives in Sexual and Reproductive Health 42(4): 251-7. doi: 10.1363/4225110.

Krenn, S. et al. 2014. "Using behavior change communication to lead a comprehensive family planning program: the Nigerian Urban Reproductive Health Initiative," Global Health: Science and Practice 2(4): 427-443. doi: 10.9745/GHSP-D-14-00009.

Lee, S.H., et al. 2016. "Effectiveness of mHealth interventions for maternal, newborn and child health in low- and middleincome countries: systematic review and meta-analysis," Journal of Global Health 6(1): 010401. doi: 10.7189/ jogh.06.010401.

LeFevre, A.E. et al. 2017. "Mobile technology for community health in Ghana: what happens when technical functionality threatens the effectiveness of digital health programs?," Bmc Medical Informatics and Decision Making 17(1): 27. doi: 10.1186/s12911-017-0421-9.

Lin, L., M. Jung, R.F. McCloud, and K. Viswanath. 2014. "Media use and communication inequalities in a public health emergency: a case study of 2009-2010 pandemic influenza A virus subtype H1N1," Public Health Reports 129(Suppl4): 49-60.

Liu, D. and R.F. Baumeister. 2016. Social networking online and personality of self-worth: A meta-analysis. Journal of Research in Personality, 64: 79-89. doi: 10.1016/j.jrp.2016.06.024.

Livingstone, S., A. Nandi, S. Banaji, and M. Stoilova. 2017. Young Adolescents and Digital Media: uses, risks and opportunities in low-and middle-income countries: a rapid evidence review. London: Gage.

Lund, S. et al. 2012. "Mobile phones as a health communication tool to improve skilled attendance at delivery in Zanzibar: a cluster-randomised controlled trial," BJOG: An International Journal of Obstetrics \& Gynaecology 119(10): 1256-1264. doi: 10.1111/j.1471-0528.2012.03413.x.

Marie Stopes International. 2016. The MSI Behaviour Change Framework. Guidelines for use. London: MSI.

McCarthy, O. et al. 2018. "A randomized controlled trial of an intervention delivered by mobile phone app instant messaging to increase the acceptability of effective contraception among young people in Tajikistan," Reproductive Health 15(1): 28. doi: 10.1186/s12978-018-0473-z.

Ministère de la Santé et de la Lutte conte le SIDA. 2016. Politique Nationale de Santé des Adolescents et des Jeunes 2016-2020. Abidjan: Government of Cote d'Ivoire. https://www.prb. org/wp-content/uploads/2018/05/Politique-Nationale-de- 
Sante\%CC\%81-des-Adolescents-et-des-Jeunes-2016-2020.Co\%CC\%82te-d\%E2\%80\%99Ivoire.pdf (Accessed 27 March 2019).

Ministère de la Santé /GoBF. 2015. Plan Stratégique Santé des Adolescents et des Jeunes 2015-2020. Ouagadougou. Burkina Faso. https://stage.prb.org/wp-content/uploads/2018/05/ Plan-Strate\%CC\%81gique-Sante\%CC\%81-des-Adolescents-etdes-Jeunes-2015-2020.-Burkina-Faso.pdf (Accessed 27 March 2019).

Naugle, D.A. and R.C. Hornik. 2014. "Systematic review of the effectiveness of mass media interventions for child survival in low-and middle-income countries," Journal of Health Communication 19(supp1): 190-215. doi: 10.1080/10810730.2014.918217.

Nominet. 2016. Improving internet access in Africa. https://www. nominet.uk/improving-internet-access-africa/ (Accessed 27 March 2019).

Obasola, O.I., I. Mabawonku, and I. Lagunju. 2015. "A review of e-health interventions for maternal and child health in sub-Sahara Africa," Maternal and Child Health Journal 19(8): 1813-1824. doi: 10.1007/s10995-015-1695-0.

Oyeyemi, S.O. and Wynn, R. 2014. "Giving cell phones to pregnant women and improving services may increase primary health facility utilization: a case-control study of a Nigerian project," Reproductive Health 11(1): 8. doi: 10.1186/1742-475511-8.

Peiris, D., D. Praveen, C. Johnson, and K. Mogulluru. 2014. "Use of $\mathrm{mHealth}$ systems and tools for non-communicable diseases in low-and middle-income countries: a systematic review," Journal of Cardiovascular Translational Research 7(8): 677-691. doi: 10.1007/s12265-014-9581-5

Pew Research Center. 2018. Majorities in sub-Saharan Africa own mobile phones, but smartphone adoption is modest. https:// www.pewglobal.org/2018/10/09/majorities-in-sub-saharanafrica-own-mobile-phones-but-smartphone-adoption-ismodest/ (Accessed 27 March 2019).

Poushter, J. 2016. "Smartphone ownership and internet usage continues to climb in emerging economies." Washington, DC: Pew Research Center.

Radzik, M., S. Sherer, and L.S. Neinstein. 2002. "Psychosocial development in normal adolescents." In L. S. Neinstein (Ed.), Adolescent Health Care: a practical guide (4th ed.), pp. 52-58. Philadelphia: Lippincott.

Rai, A.A. et al. 2003. "Relative influences of perceived parental monitoring and perceived peer involvement on adolescent risk behaviors: An analysis of six cross-sectional data sets," Journal of Adolescent Health 33(2): 108-118.

Resopopdev. 2019. Présentation des Jeunes Ambassadeurs en Santé de la Reproduction et en Planification Familiale (JASRPF). https://blogpopdev.wordpress.com/jeunes-ambassadeurs-en-sante-de-la-reproduction-et-en-planification-familiale/ (Accessed 27 March 2019).

Sawyer, S.M., P.S. Azzopardi, D. Wickremarathne, and G.C. Patton. 2018. "The age of adolescence," The Lancet: Child \& Adolescent Health 2(3): 223-228.
Smith, C. et al. 2015. "Mobile phone-based interventions for improving contraception use," Cochrane Database Syst Rev. 2015(6): CD011159. doi: 10.1002/14651858.CD011159.pub2.

Smith, C. et al. 2016. Mobile Technology for Improved Family Planning (MOTIF): the development of a mobile phone-based (mHealth) intervention to support post-abortion family planning (PAFP) in Cambodia," Reproductive Health 13:1. doi: 10.1186/s12978-015-0112-x.

Sougou, N.M. et al. 2017. "Effects of behavior change communication interventions on the adoption of contraceptive methods in urban and peri-urban districts of Senegal," World 2(4): 144-150. doi: 10.11648/j.wjph.20170204.13.

Statista. 2019. The number of television households in sub-Saharan Africa. https://www.statista.com/statistics/287739/number-of-tv-households-in-sub-saharan-africa/.

Suryawanshi, D., S.K. Patel, R. Adhikary, and S. Bharat. 2016. "Does mass-media public communication campaign normalize discussion, attitude and behavior about condom use among married men in India," J AIDS Clin Res 7(599): 2. doi:10.4172/21556113.1000599.

Taylor, M. et a.. 2010. "Changing sexual behaviour to reduce HIV transmission-a multi-faceted approach to HIV prevention and treatment in a rural South African setting," AIDS Care 22(11): 1395-1402. doi: 10.1080/09540121003720960.

Trent, M., C. Thompson, and K. Tomaszewski. 2015. "Text messaging support for urban adolescents and young adults using injectable contraception: outcomes of the DepoText pilot trial," Journal of Adolescent Health 57(1): 100-106. doi: 10.1016/j.jadohealth.2015.03.008.

Ubongo. 2019. The future of television in sub-Saharan Africa. https://www.ubongo.org/the-future-of-television-in-sub-saharan-africa-in-5-statistics/ (Accessed 27 March 2019).

Undie, C. et al. 2014. "Community-based interventions can expand access to comprehensive reproductive health and HIV information and services for married adolescent girls," International Journal of Child and Adolescent Health 7(1): 23-35.

United Nations Committee for Development Policy. 2018. "List of least developed countries (as of December 2018." New York City: United Nations. https://www.un.org/development/desa/ dpad/wp-content/uploads/sites/45/publication/ldc_list.pdf (Accessed 27 March 2019).

United Nations Fund for Population Activities (UNFPA). 2017. Regional strategy for social and behaviour change communication (SBCC) 2017-2019. https://Wcaro.Unfpa.Org/Sites/Default/Files/Pub-Pdf/Summaryensbcc.pdf (Accessed 27 March 2019).

Vahdat, H.L. et al. 2013. "There are some questions you may not ask in a clinic: providing contraception information to young people in Kenya using SMS," International Journal of Gynaecology and Obstetrics 123(suppl 1): e2-e6. doi: 10.1016/j. ijgo.2013.07.009.

Wakefield, M.A., B. Loken, and R.C. Hornik. 2010. "Use of mass media campaigns to change health behaviour," The Lancet 376(9748): 1261-1271. 
Wells, E. 2015. Countering myths and misperceptions about contraceptives. Seattle: PATH. https://www.path.org/publications/files/RH_outlook_myths_mis_june_2015.pdf. (Accessed 27 March 2019).

Whittaker, R. et al. 2016. "Mobile phone-based interventions for smoking cessation," Cochrane Database of Systematic Reviews 4: CD006611. doi: 10.1002/14651858.CD006611.pub4.

Winston, J. et al. 2018. "Impact of the Urban Reproductive Health Initiative on family planning uptake at facilities in Kenya, Nigeria, and Senegal," BMC Women's Health 18(1): 9. doi: 10.1186/ s12905-017-0504-X.

Winters, M. et al. 2018. "Risk communication and Ebola-specific knowledge and behavior during 2014-2015 outbreak, Sierra Leone," Emerging Infectious Diseases 24(2): 336-344. https:// dx.doi.org/10.3201/eid2402.171028.

World Bank. 2016. “Experimental evaluation of MTV Shuga: changing social norms and behaviors with entertainment education." Washington DC: World Bank.

World Economic Forum (WEF). 2017. "The future of jobs and skills in Africa preparing the region for the fourth industrial revolution," Exectutive Brief. Geneva: WEF.

World Health Organisation. 2010. Repositioning family planning: guidelines for advocacy action. Geneva: WHO.

You Only Live Once (YOLO). 2017-2018. Annual reports, Year 3 and Year 4.

Zamawe, C.O., M. Banda, and A.N. Dube. 2016. "The impact of a community driven mass media campaign on the utilisation of maternal health care services in rural Malawi," BMC Pregnancy and Childbirth 16(1): 21. doi: 10.1186/s12884-016-0816-0. 


\section{Annex}

Selected mass media and social/ digital media interventions around SRH and FP: Approaches, evaluation methods*, impact and lessons learned

*NB Some initiatives have not been objectively evaluated and thus their impact on attitudes and behavior and lessons learned for future programming are not known. They are nevertheless included as they show potentially promising and innovative approaches. 


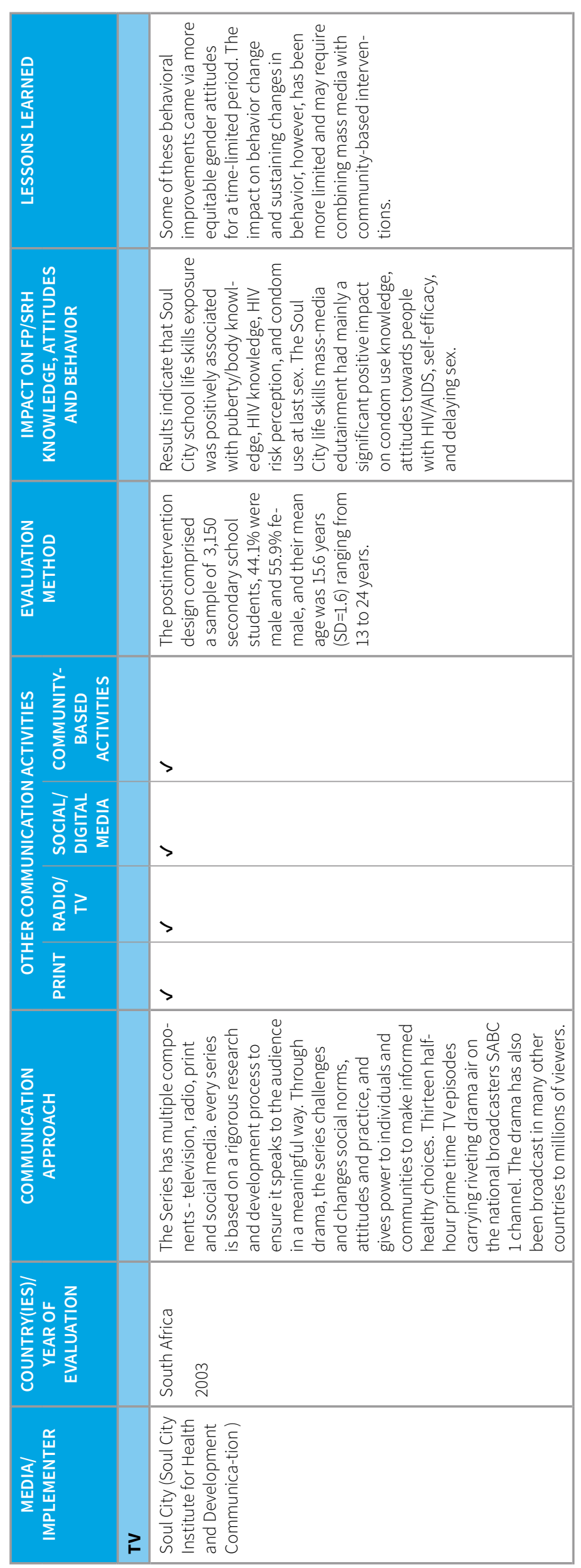




\begin{tabular}{|c|c|}
\hline 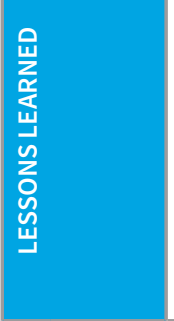 & 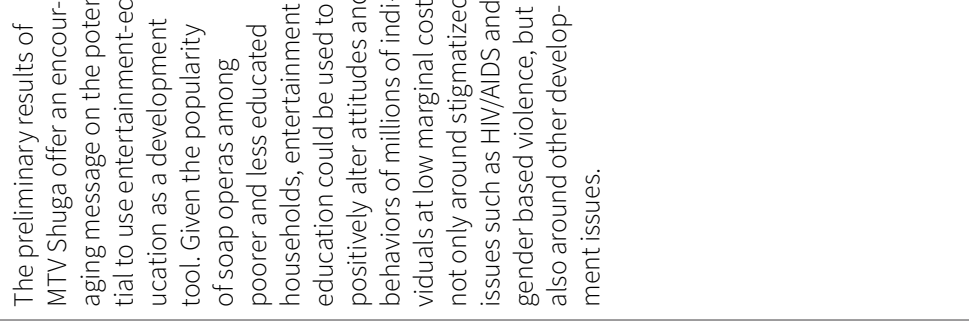 \\
\hline 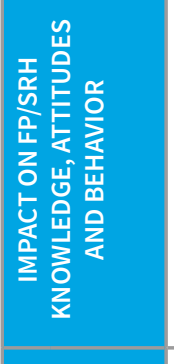 & 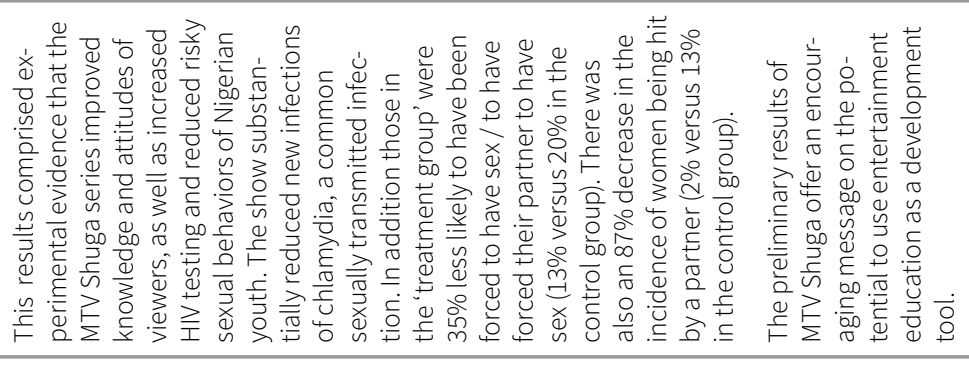 \\
\hline 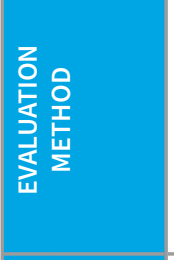 & 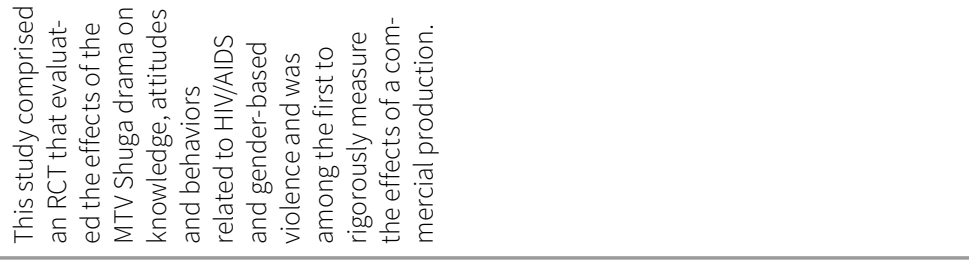 \\
\hline 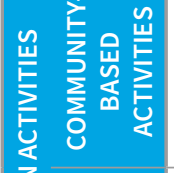 & $>$ \\
\hline 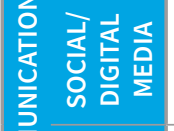 & $>$ \\
\hline 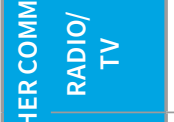 & $>$ \\
\hline 志 & \\
\hline 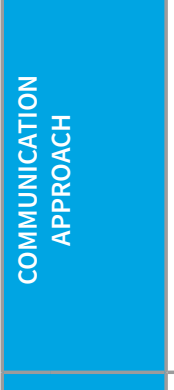 & 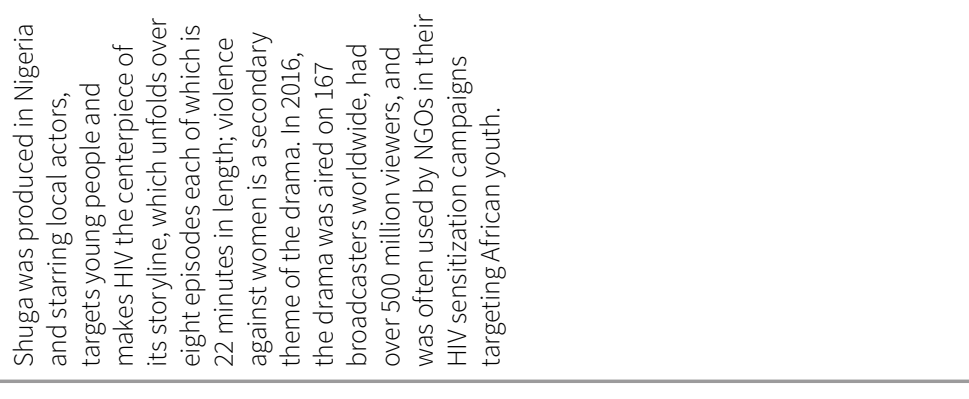 \\
\hline 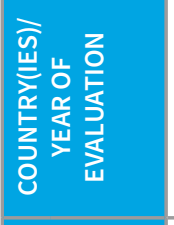 & 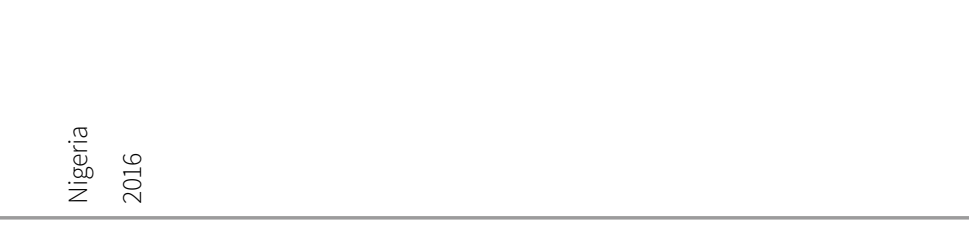 \\
\hline 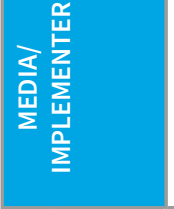 & 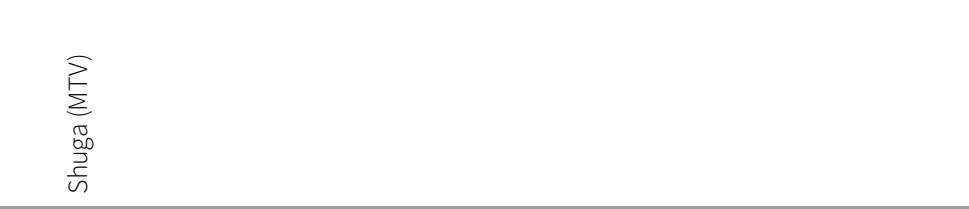 \\
\hline
\end{tabular}




\begin{tabular}{|c|c|c|}
\hline & 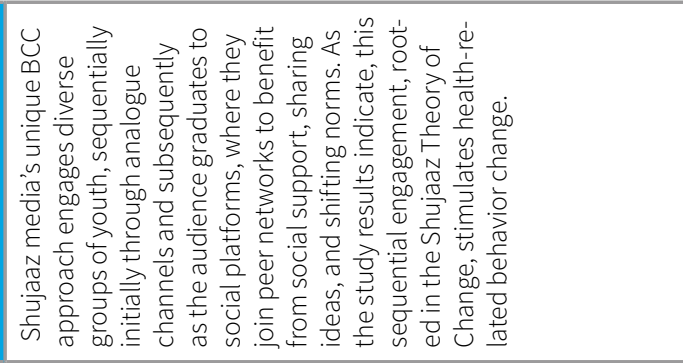 & 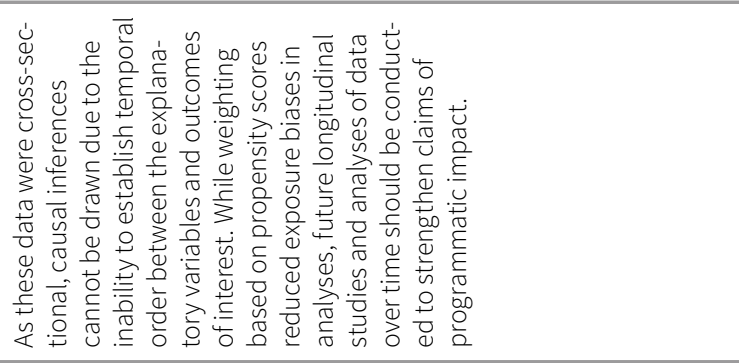 \\
\hline 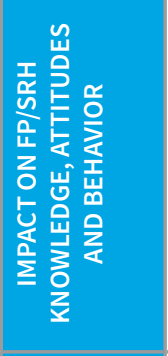 & 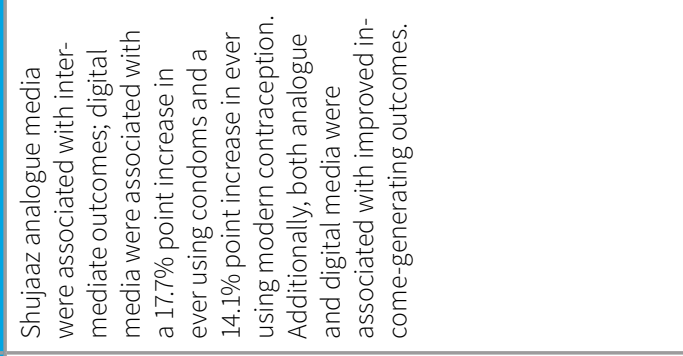 & 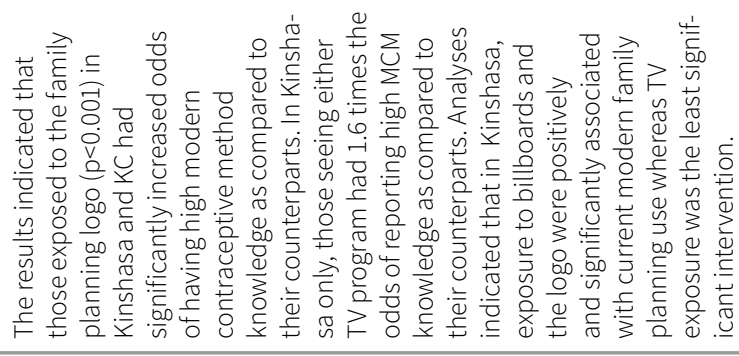 \\
\hline 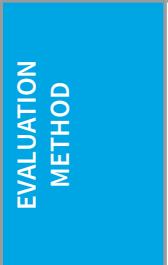 & 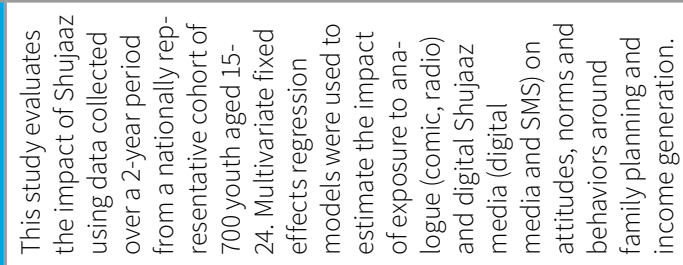 & 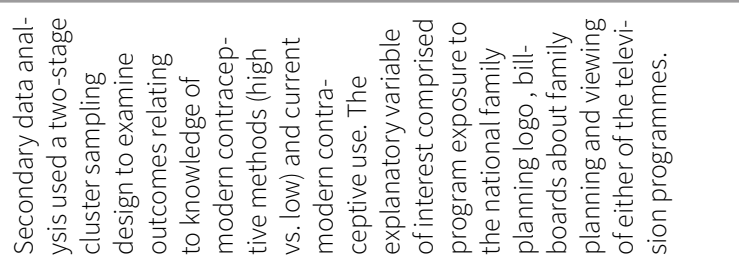 \\
\hline 䍃 & $>$ & $>$ \\
\hline 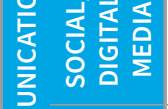 & $>$ & \\
\hline 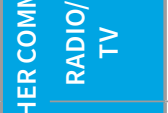 & $>$ & $>$ \\
\hline$a$ & $>$ & $>$ \\
\hline 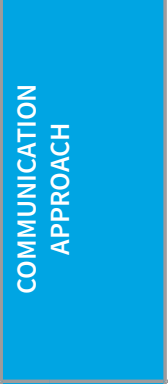 & 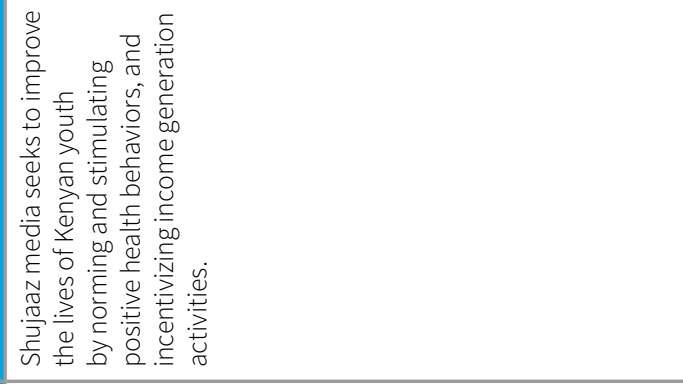 & 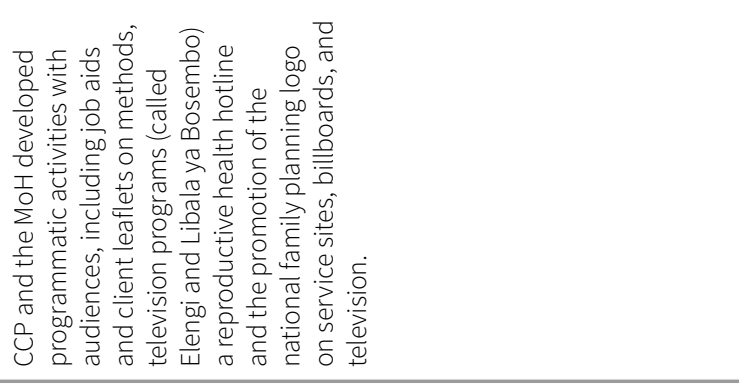 \\
\hline 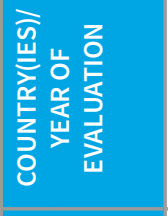 & 总 & 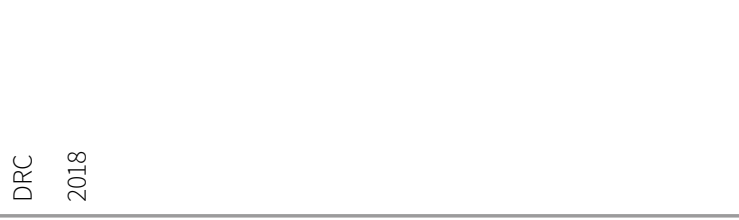 \\
\hline 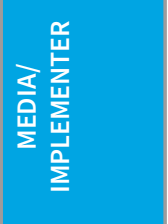 & 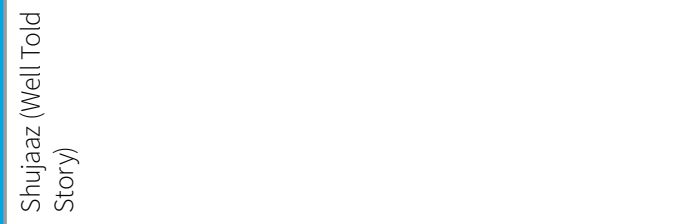 & 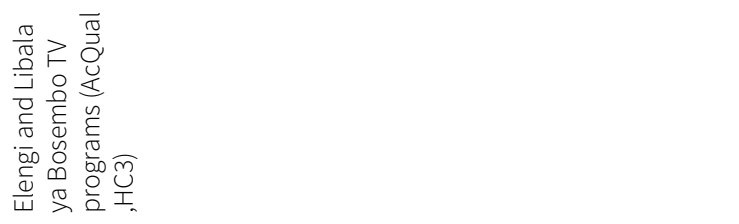 \\
\hline
\end{tabular}




\begin{tabular}{|c|c|c|}
\hline 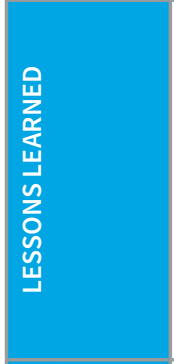 & 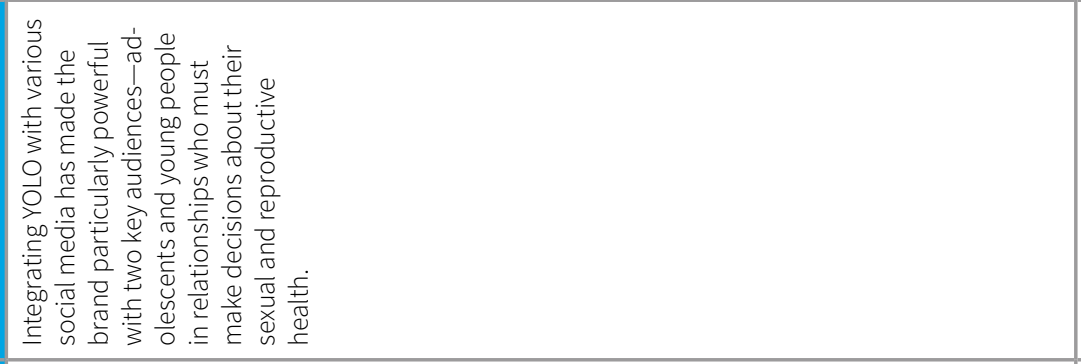 & \\
\hline 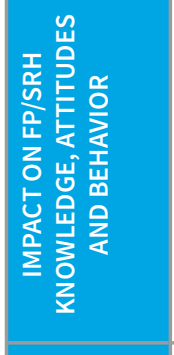 & 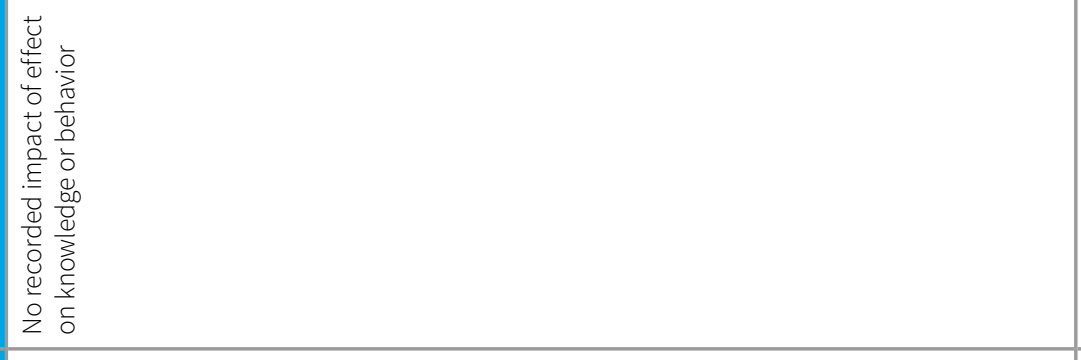 & \\
\hline 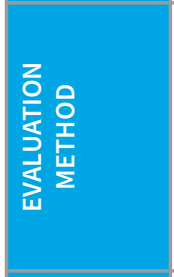 & 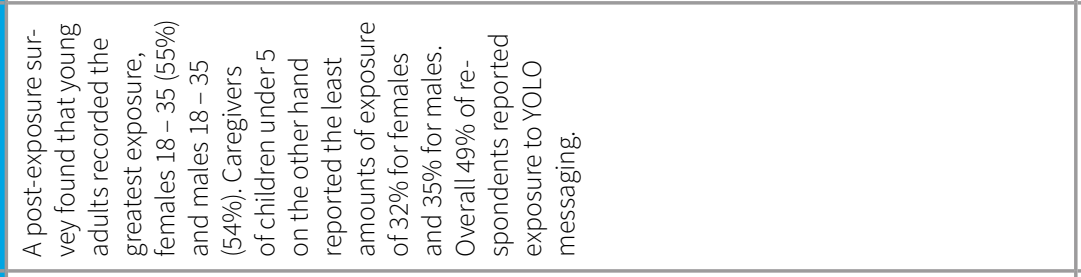 & 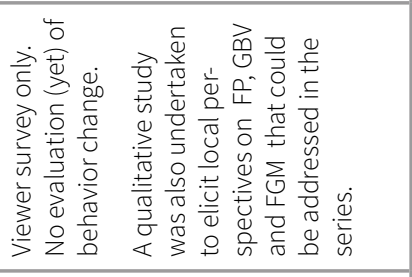 \\
\hline 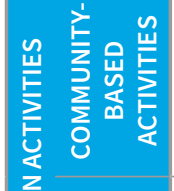 & $>$ & $>$ \\
\hline 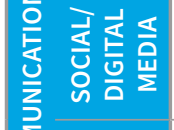 & $>$ & $>$ \\
\hline 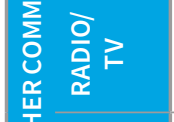 & $>$ & $>$ \\
\hline 志点 & $>$ & \\
\hline 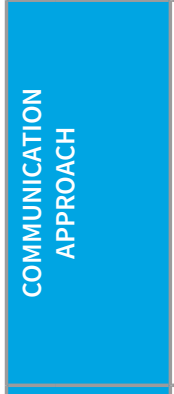 & 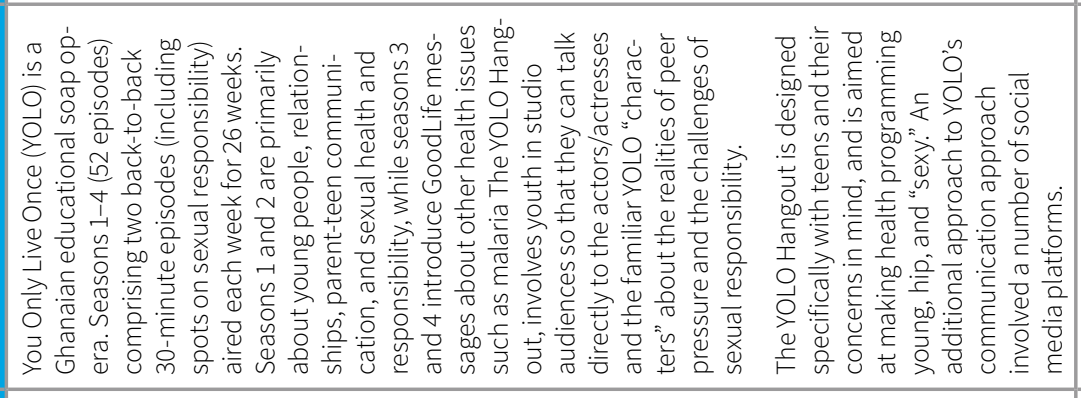 & 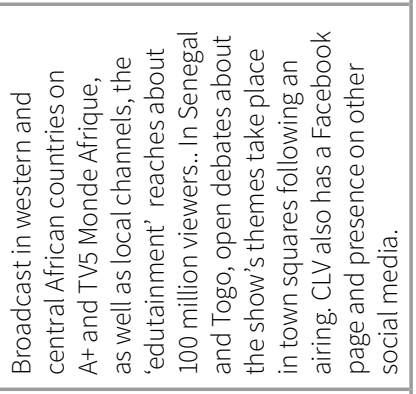 \\
\hline 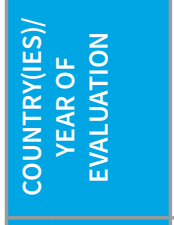 & 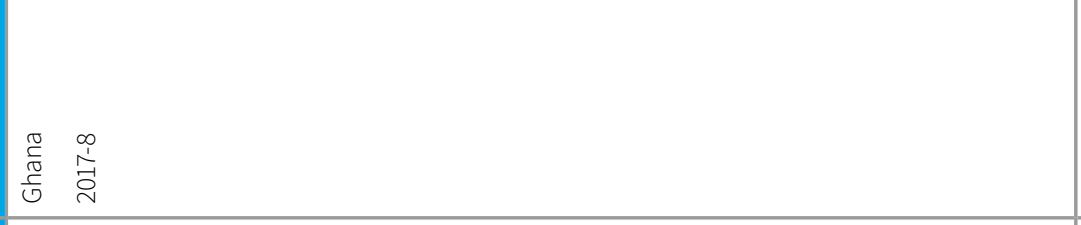 & 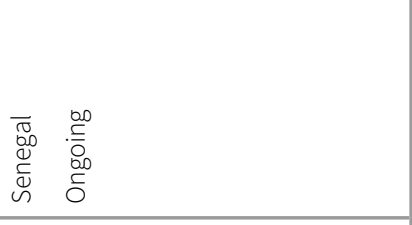 \\
\hline 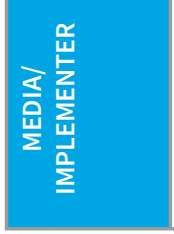 & 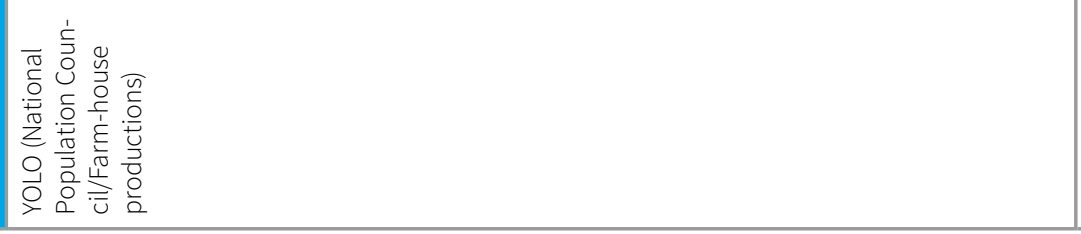 & 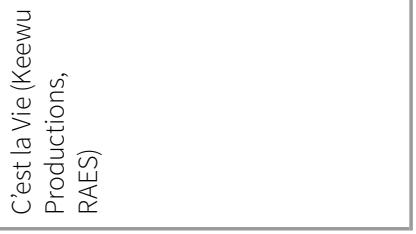 \\
\hline
\end{tabular}




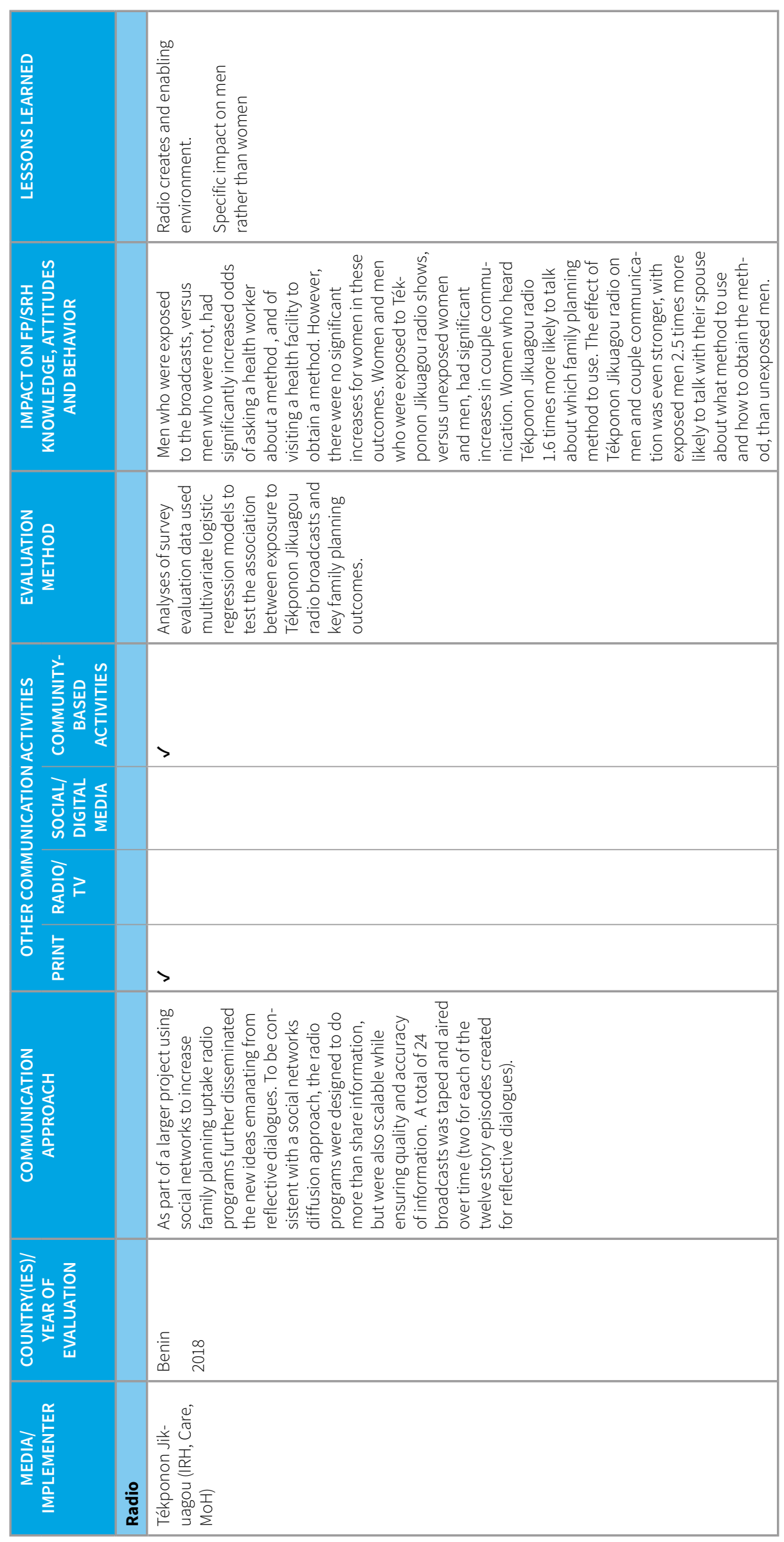




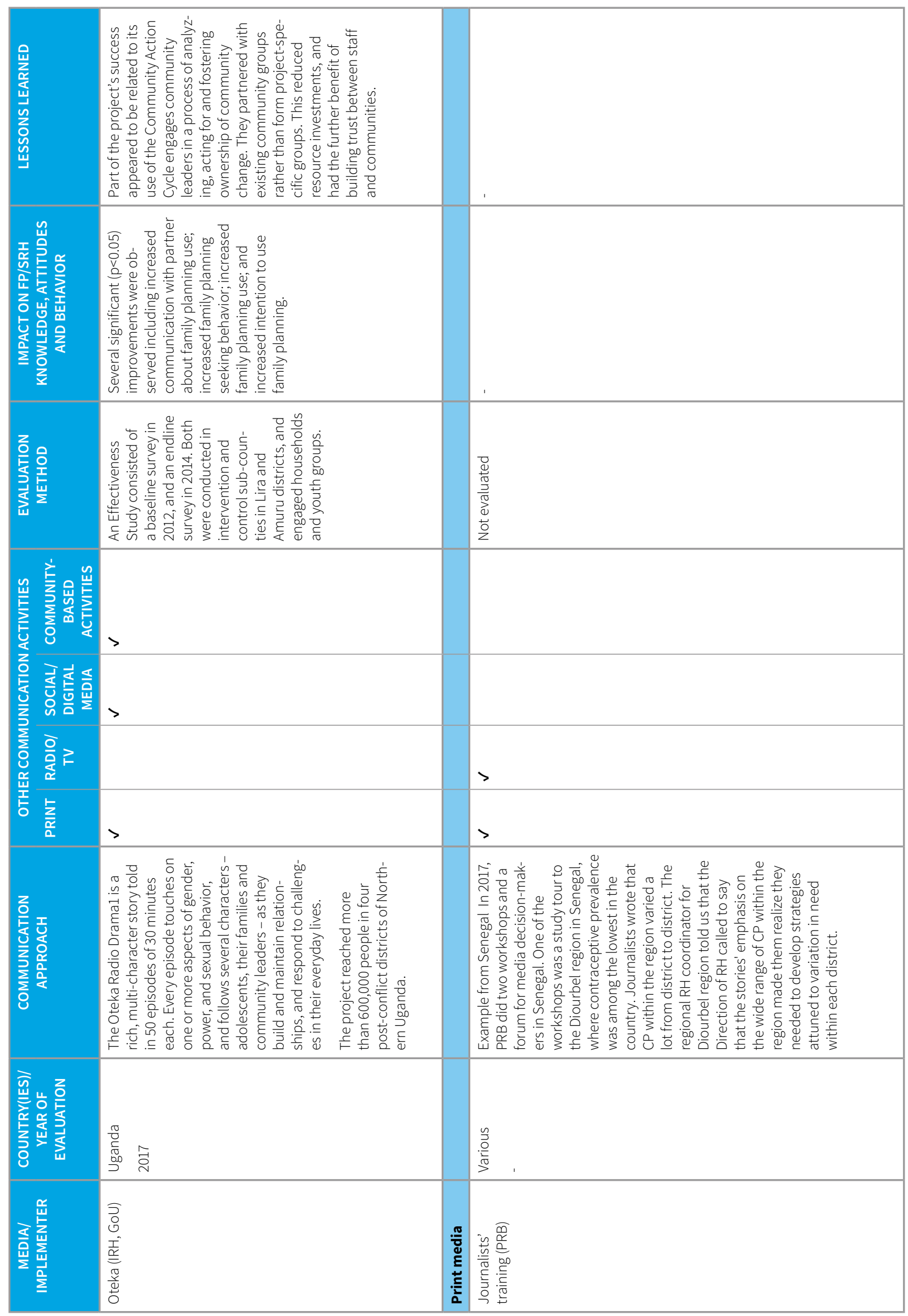




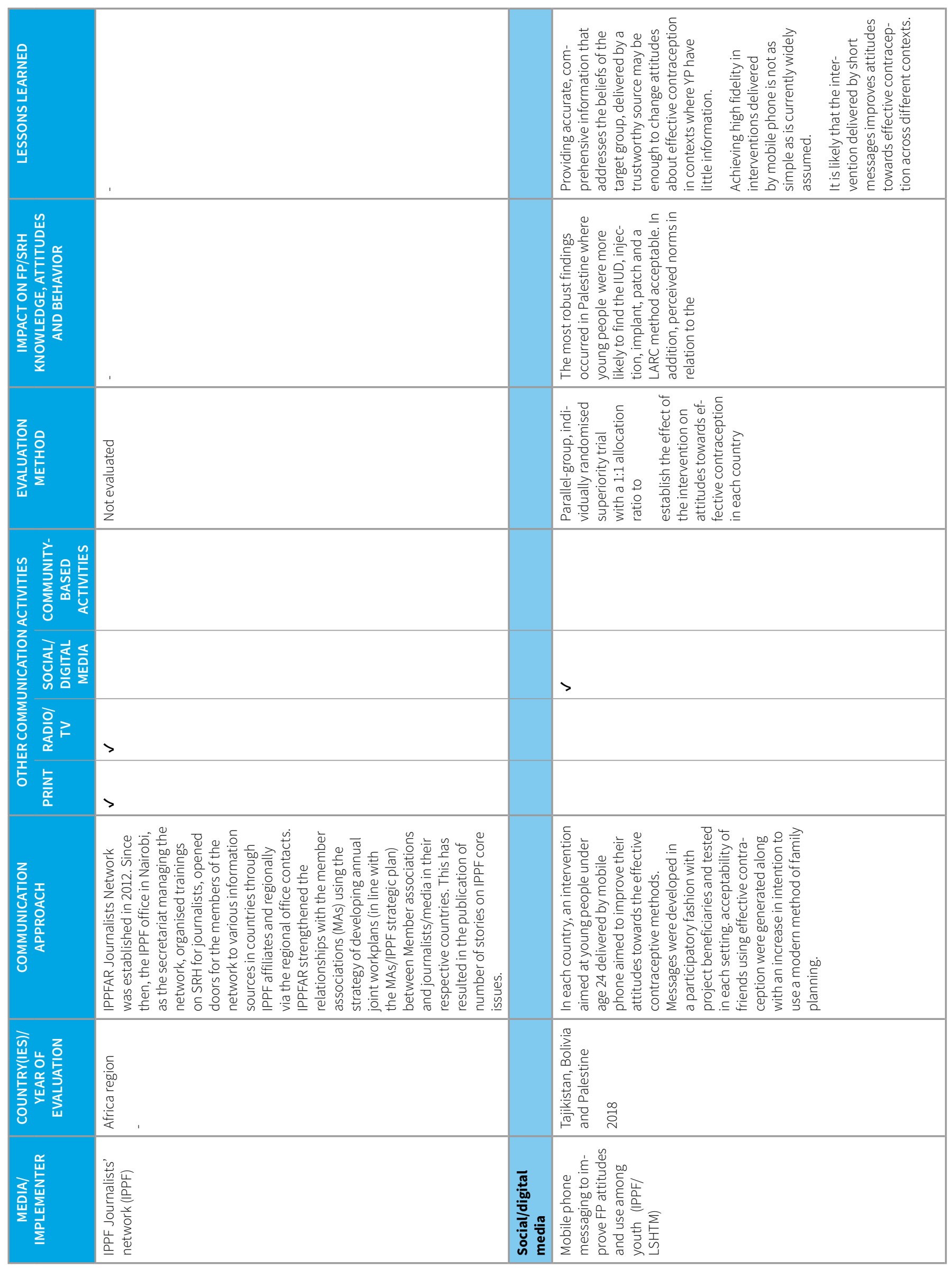




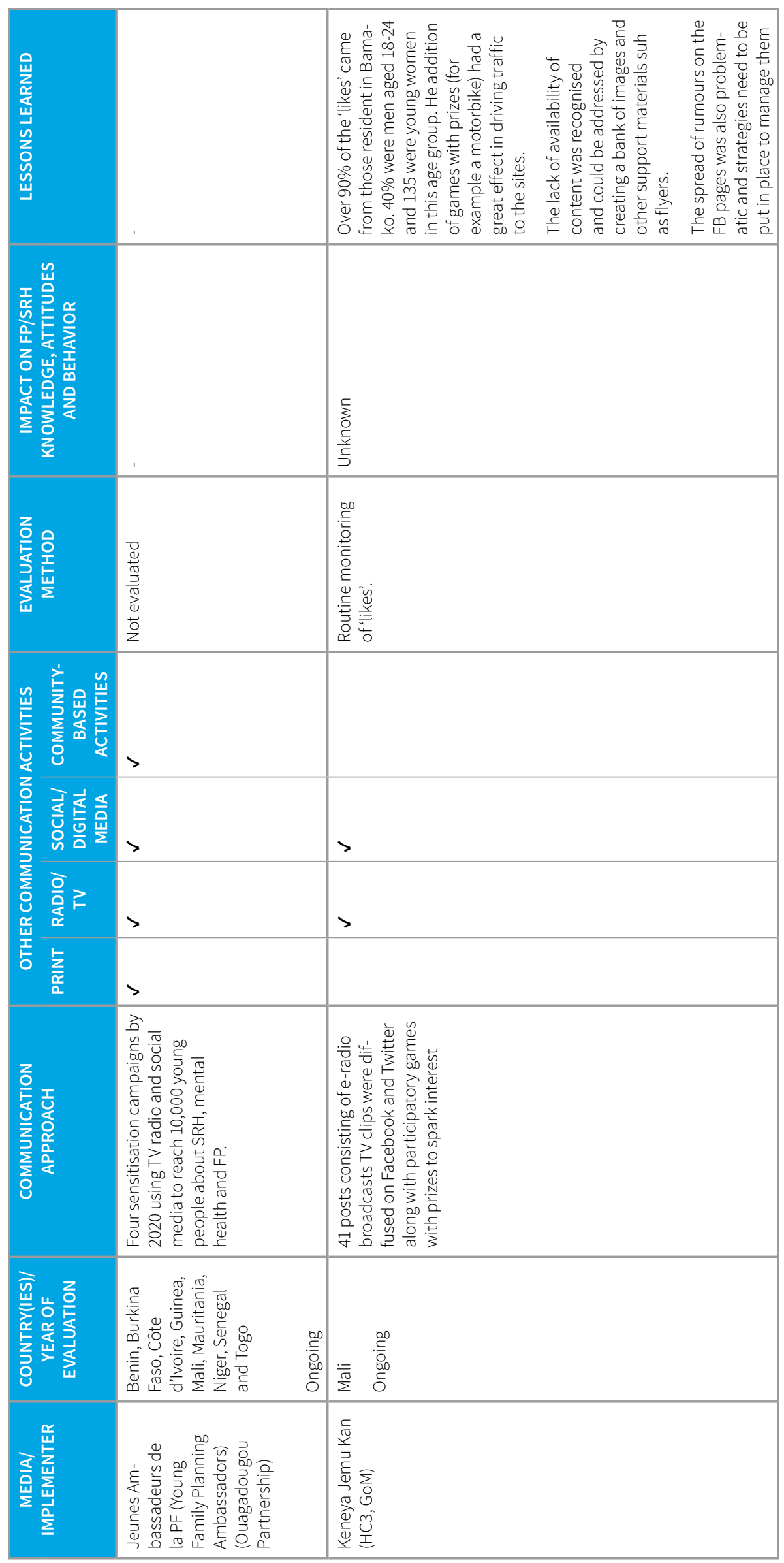




\begin{tabular}{|c|c|}
\hline & 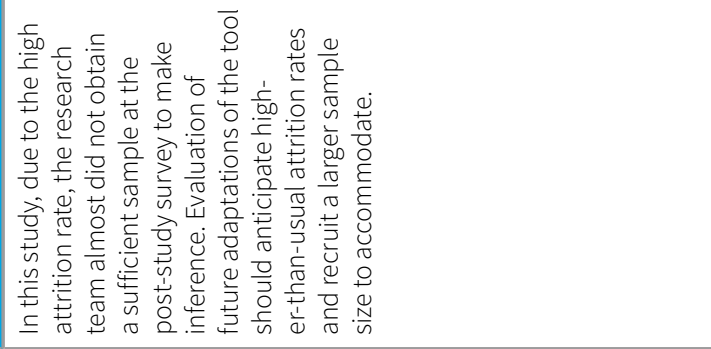 \\
\hline 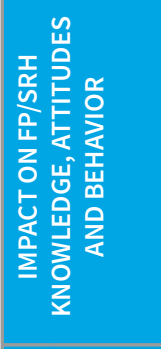 & 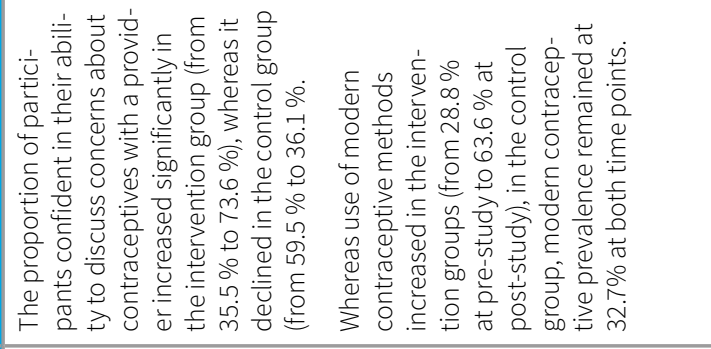 \\
\hline 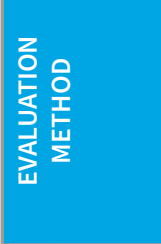 & 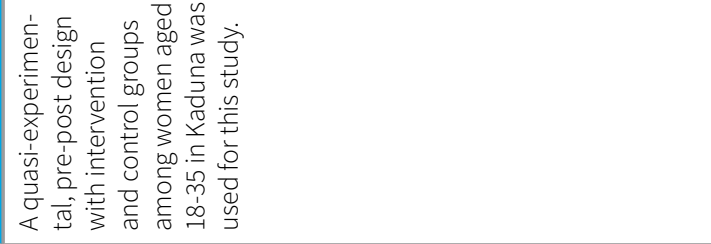 \\
\hline 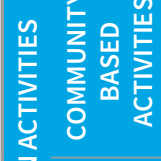 & \\
\hline 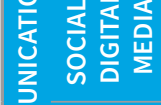 & $>$ \\
\hline 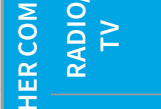 & \\
\hline 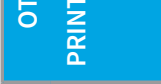 & \\
\hline 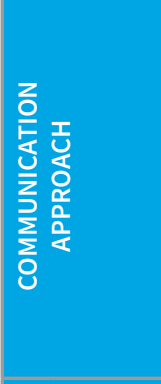 & 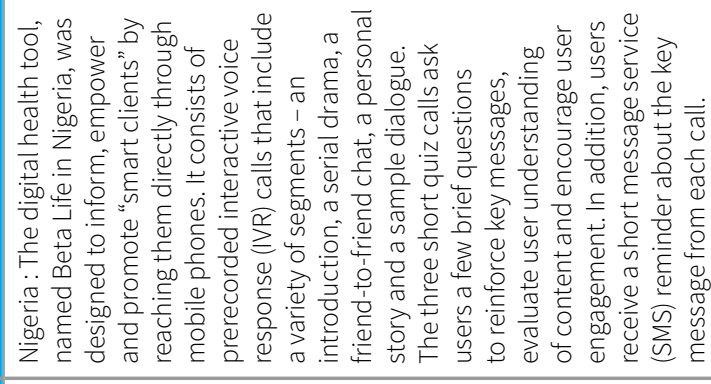 \\
\hline 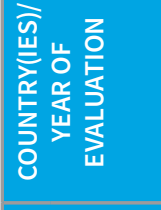 & 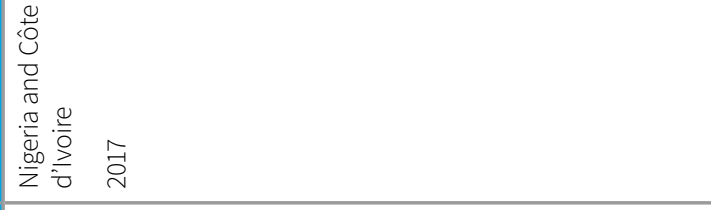 \\
\hline 总 & 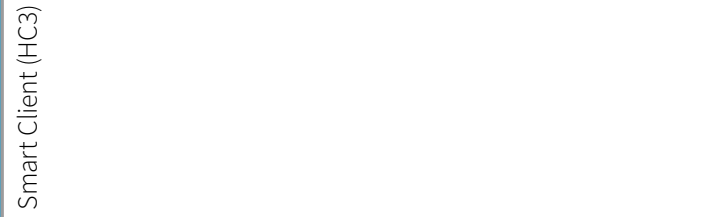 \\
\hline
\end{tabular}




\section{Population Council}

4301 Connecticut Ave., NW | Suite 280

Washington, DC 20008

+12022379400

breakthroughactionandresearch.org 